\title{
Soil carbon model alternatives for ECHAM5/JSBACH climate model: Evaluation and impacts on global carbon cycle estimates
}

\author{
T. Thum, ${ }^{1,2}$ P. Räisänen, ${ }^{1}$ S. Sevanto,,${ }^{3,4}$ M. Tuomi,${ }^{5,6}$ C. Reick, ${ }^{7}$ T. Vesala, ${ }^{3}$ T. Raddatz ${ }^{7}$ \\ T. Aalto, ${ }^{1}$ H. Järvinen, ${ }^{1}$ N. Altimir, ${ }^{8}$ K. Pilegaard,${ }^{9}$ Z. Nagy, ${ }^{10,11}$ S. Rambal, ${ }^{12}$ \\ and J. Liski ${ }^{5}$
}

Received 12 November 2010; revised 10 March 2011; accepted 17 March 2011; published 29 June 2011.

[1] The response of soil organic carbon to climate change might lead to significant feedbacks affecting global warming. This response can be studied by coupled climatecarbon cycle models but so far the description of soil organic carbon cycle in these models has been quite simple. In this work we used the coupled climate-carbon cycle model ECHAM5/JSBACH (European Center/Hamburg Model 5/Jena Scheme for Biosphere-Atmosphere Coupling in Hamburg) with two different soil carbon modules, namely (1) the original soil carbon model of JSBACH called CBALANCE and (2) a new soil carbon model Yasso07, to study the interaction between climate variability and soil organic carbon. Equivalent ECHAM5/JSBACH simulations were conducted using both soil carbon models, with freely varying atmospheric $\mathrm{CO}_{2}$ for the last 30 years (1977-2006). In this study, anthropogenic $\mathrm{CO}_{2}$ emissions and ocean carbon cycle were excluded.

The new model formulation produced soil carbon stock estimates that were much closer to measured values. It also captured better the seasonal cycle of the direct $\mathrm{CO}_{2}$ exchange measurements at the three grassland sites considered (RMS error reduced by $12 \%$ ), while for the five forest sites also analyzed, the results were ambiguous and the RMS error was 12\% larger for Yasso07 than for CBALANCE. As a response to climatic changes, Yasso07 showed greater release of soil carbon to the atmosphere than the original model formulation during the years 1977-2006. This emphasizes the need for better understanding the processes affecting soil carbon stocks and their turnover rates to predict the climatic feedbacks.

Citation: Thum, T., et al. (2011), Soil carbon model alternatives for ECHAM5/JSBACH climate model: Evaluation and impacts on global carbon cycle estimates, J. Geophys. Res., 116, G02028, doi:10.1029/2010JG001612.

\section{Introduction}

[2] The response of soil carbon stocks to changing climate is one of the hot topics in climate change research today. Carbon cycle feedbacks are predicted to increase the atmospheric $\mathrm{CO}_{2}$ concentration, but the current estimates of their contribution to the projected $\mathrm{CO}_{2}$ concentration at the end of the 21 st century vary widely, from 20 to 200 ppmv, between different carbon-climate models [Friedlingstein et al., 2006]. One significant source of uncertainty in these estimates is the modeling of the soil carbon cycle [Friedlingstein et al., 2006]. Previous modeling studies show that warming of the climate

\footnotetext{
${ }^{1}$ Climate Change Research, Finnish Meteorological Institute, Helsinki, Finland.

${ }^{2}$ Now at Le Laboratoire des Sciences du Climat et 1'Environnement, CEA-Orme des Merisiers, Gif-sur-Yvette, France.

${ }^{3}$ Department of Physics, University of Helsinki, Helsinki, Finland.

${ }^{4}$ Now at Earth and Environmental Sciences Division, Los Alamos National Laboratory, Los Alamos, New Mexico, USA.

${ }^{5}$ Research Programme for Global Change, Finnish Environment Institute, Helsinki, Finland.

Copyright 2011 by the American Geophysical Union. 0148-0227/11/2010JG001612
}

will decrease soil carbon storage whereas $\mathrm{CO}_{2}$ fertilization is shown to increase the soil carbon reserves [Davi et al., 2006; Harrison et al., 2008]. Therefore, it still remains an open question whether changes in soil carbon will accelerate climate change [Heimann and Reichstein, 2008].

[3] The formulations of soil carbon responses to climate in global coupled carbon-climate models are currently quite simple. Most approaches are based on the $\mathrm{Q}_{10}$ approach, where constant temperature sensitivity of respiration is presumed. A global value for $\mathrm{Q}_{10}$ has been under debate [Zhou et al., 2009], but recently a convergence for the global value was found at the ecosystem level [Mahecha et al., 2010]. Other types of temperature dependencies based on

\footnotetext{
${ }^{6}$ Department of Mathematics and Statistics, University of Helsinki, Helsinki, Finland.

${ }^{7}$ Max Planck Institute for Meteorology, Hamburg, Germany.

${ }^{8}$ Forest Technology Centre of Catalonia, Solsona, Spain.

${ }^{9}$ Biosystems Division, Risø National Laboratory for Sustainable Energy, Technical University of Denmark, Roskilde, Denmark.

${ }^{10}$ Institute of Botany and Ecophysiology, Szent Istvan University, Godollo, Hungary.

${ }^{11}$ Plant Ecological Research Group, Hungarian Academy of Sciences, Szent Istvan University, Godollo, Hungary.

${ }^{12}$ Dream CEFE-CNRS, Montpellier, France.
} 
more detailed considerations of different processes involved have also been studied [Agren and Wetterstedt, 2007]. Models also differ in their conceptual description of soil carbon, by either locating the soil carbon in separate pools or by decribing it using a distribution [Yurova et al., 2010]. Despite finding a global value for $\mathrm{Q}_{10}$, and calibrating models using of large data sets [Raich and Schlesinger, 1992; Raich and Potter, 1995] or detailed laboratory experiments [Yurova et al., 2010], problems still remain regarding the applicability of the present models at the global scale.

[4] While most of the discussion has focused on temperature, the simulations of potential future climate scenarios also predict changes in the spatial and temporal distribution of precipitation. Precipitation has a great impact on respiration rates [Heimann and Reichstein, 2008] and these changes might lead to significant effects on the soil carbon storage at the global scale. Precipitation has been predicted to increase at high latitudes and decrease in subtropical land regions [Intergovernmental Panel on Climate Change, 2007], which together with warming climate could enhance carbon release from soil at high latitudes but reduce it in subtropical regions. The combined effects of changing precipitation patterns and warming temperatures need to be modeled realistically to predict their probably remarkable effects on the atmospheric $\mathrm{CO}_{2}$ content.

[5] In this study we compared two different approaches to model soil carbon cycling as a part of a global climate model consisting of the ECHAM5 atmospheric GCM (General Circulation Model) and the JSBACH terrestrial biosphere model. One of the approaches was the original, $\mathrm{Q}_{10}$-based soil carbon scheme of JSBACH called CBALANCE. The other was the Yasso07 model [Tuomi et al., 2009], which is a model that takes the chemical composition of the falling litter and soil carbon reserves into account thus enabling differentiation of the effects of plant functional types (PFTs) on soil carbon reserves explicitly. Earlier global carbon models, such as models based on CENTURY [Parton et al., 1988], do not account for the chemical composition but consider the lignin content of the litter only [Krinner et al., 2005].

[6] Our model simulations serve two objectives: (1) First, to evaluate the performance of the ECHAM5/JSBACH model in simulating soil carbon storage and carbon fluxes, separately for the two soil carbon models Yasso07 and CBALANCE. This is done by comparing model results to global soil carbon data sets and micrometeorological measurements. (2) Second, to estimate changes in the carbon budget of terrestrial ecosystems between 1977 and 2006 in response to changes in climate conditions using these alternative soil carbon modules. Both model versions suggest that changes in climate have led to a net release of carbon from soil even when land use change and anthropogenic emissions are excluded from the analysis, and that this net release has contributed to increased atmospheric $\mathrm{CO}_{2}$ concentration. The resulting increase in the atmospheric $\mathrm{CO}_{2}$ is, however, greater for Yasso07 than for the original model formulation.

\section{Model Description and Evaluation Data}

\subsection{ECHAM5 Atmospheric Model and JSBACH Terrestrial Biosphere Model}

[7] The global climate model used in this study consists of the ECHAM5 (Version 5.4 [Roeckner et al., 2003, 2006]) atmospheric GCM and the JSBACH terrestrial biosphere model [Raddatz et al., 2007]. The dynamical part of ECHAM5 is formulated in spherical harmonics, while physical parameterizations are computed in grid point space. The simulations reported here used a horizontal resolution of T63 (a grid spacing of $1.875 \mathrm{deg}$ ) with 31 layers in the vertical and the model top at $10 \mathrm{hPa}$. A semi-implicit time integration scheme is used for model dynamics with a time step of $12 \mathrm{~min}$.

[8] The land surface model of standard ECHAM5 was replaced some years ago by the modular land surface scheme JSBACH [Raddatz et al., 2007]. By introducing JSBACH, all land surface processes formerly scattered across ECHAM, except for the lateral discharge, are now accessed by a single well defined subroutine interface. In addition, when developing JSBACH, an explicit representation of the biosphere was introduced, to account for biophysical and biogeochemical aspects of vegetation relevant to climate. For this purpose parts of the land biosphere model BETHY [Knorr, 2000] were adapted. JSBACH includes now a photosynthesis module following Farquhar et al. [1980] for C3 plants and Collatz et al. [1992] for $\mathrm{C} 4$ plants. 13 plant functional types (PFT) are distinguished by maximum carboxylation rate, maximum electron transport rate, specific leaf area carbon content, and phenology type. The spatial distribution of the PFTs is prescribed by maps. Up to four PFTs are allowed to cooccur in each model grid cell. The interplay between the $\mathrm{CO}_{2}$ assimilation rate and stomatal conductance is explicitly modeled. Both quantities therefore depend on temperature, soil moisture, water vapor deficit (VPD), as well as $\mathrm{CO}_{2}$ concentration of the ambient air, and the absorption of solar visible radiation, which is computed for three canopy layers.

[9] Under present climate conditions and present atmospheric $\mathrm{CO}_{2}$ concentration, JSBACH gives a global net primary productivity (NPP) of about $60-70 \mathrm{PgC} \mathrm{yr}^{-1}$. This produced carbon is allocated to terrestrial biomass. There are five phenotypes of vegetation: evergreen, summergreen, raingreen forest or shrubland, grassland, and managed (nonforest) areas. This phenology scheme is completely independent of predefined calendar dates and solely driven by temperature, soil moisture and NPP [Raddatz et al., 2007]. The leaf area index (LAI) computed by the phenology scheme enters the calculation of albedo, which is needed for calculating the radiation balance of the atmosphere. The models for soil hydrology and soil heat transport are adapted from standard ECHAM5 [Roeckner et al., 2003] and the land surface energy balance is solved within JSBACH.

\subsection{Soil Carbon Models}

[10] In JSBACH, the carbon produced in plants is divided into three pools: a wood pool, a pool representing active plant tissue (leaves, fine roots, etc.), and a pool of reserve carbon (starch, sugars). From the latter two pools carbon is transferred to the soil at a rate proportional to the leaf shedding rate, whereas wood is decomposed into soil assuming a fixed life time. To describe the mineralization of organic carbon in the soils, we used two alternative models, CBALANCE based on a standard $\mathrm{Q}_{10}$ formulation [Raddatz et al., 2007], and Yasso07 using a more mechanistic approach [Tuomi et al., 2009]. 
Table 1. The Turnover Times (i.e., Decomposition Rates ${ }^{-1}$ ) of CBALANCE in Reference Conditions (Soil Temperature $\mathrm{T}_{\text {soil }}=$ $0^{\circ} \mathrm{C}$ and Soil Moisture at Field Capacity $\eta=1$ (see Equation (1))) and of Yasso07 in Years in Reference Conditions (Air Temperature $\mathrm{T}=0^{\circ} \mathrm{C}$ and Precipitation $P_{a} \rightarrow \infty$, i.e., Decomposition Not Limited by Lack of Moisture (see Equation (2)))

\begin{tabular}{lc}
\hline Carbon Pool & Turnover Times (years) \\
\hline CBALANCE & \\
Fast pool & 1.5 \\
Slow pool & 150 \\
Yasso07 & \\
Water-soluble & 0.23 \\
Acid-soluble & 1.52 \\
Ethanol-soluble & 2.86 \\
Nonsoluble & 4.55 \\
Coarse litter & 71.4 \\
Humus & 3000 \\
\hline
\end{tabular}

[11] In the CBALANCE model, the belowground carbon consists of a fast decomposing and a slowly decomposing carbon pool. At reference conditions (soil temperature $T_{\text {soil }}=$ $0^{\circ} \mathrm{C}$, and soil moisture at field capacity $\eta=1$ ), the turnover rate of the fast carbon pool is 1.5 years while that of the slow pool is 150 years. In both cases, the heterotrophic respiration $R$ is described by

$$
R_{i}=\eta Q_{10}^{T_{\text {soil }} / 10^{\circ} \mathrm{C}} c_{i} / \tau_{i}
$$

where the subscript $i$ denotes either the fast pool or the slow pool, $c_{i}$ is the size of the pool at the previous time step and $\tau_{i}$ is the turnover rate of the pool at reference conditions. The parameter $Q_{10}$ is taken to be 1.8 , based on earlier studies [Raddatz et al., 2007; Roeckner et al., 2010] where model parameters were adjusted so as to realistically simulate the observed rise in the atmospheric $\mathrm{CO}_{2}$ concentration. The $\mathrm{CO}_{2}$ flux resulting from heterotrophic respiration is released from these two different soil carbon pools. It is calculated daily based on soil humidity and soil temperature of the previous day as well as LAI and NPP (affecting through the litter fall into soil). The soil temperature used in CBALANCE is simulated at $30-120 \mathrm{~cm}$ below the surface. Soil moisture content is described as a fraction relative to the maximum water content available to plants [Knorr and Heimann, 2001]. A fixed fraction of the decomposing carbon of the fast pool is moved to the slow pool. This fraction is set to 0.22 for most PFTs, but a lower value $(0.18)$ is used for tropical forest having fast decomposition rates [Powers et al., 2009] and a higher value (0.28) for grasslands having slow decomposition rates [Bontti et al., 2009].

[12] The soil carbon model Yasso07 describes the soil carbon mineralization in a more detailed manner than CBALANCE. Yasso07 is a new version of the widely used Yasso model [Liski et al., 2005], having now chemically distinct pools for soil carbon. In Yasso07, soil carbon is divided into six different carbon pools. The fast decomposing carbon is divided into four separate pools according to the solubility of the material: ethanol-soluble, water-soluble, acid hydrolysable and those neither soluble nor hydrolysable. These four carbon pools together will henceforth be called as EWAN pools. The fifth pool is the very slowly decomposing humus pool. Finally, the sixth pool is a pool of coarse woody litter.
[13] The parameterization of the Yasso07 model is based on an extensive data set with wide geographical coverage including litter bag and soil carbon stock measurements (but not, for example, $\mathrm{CO}_{2}$ measurements) [see Tuomi et al., 2009]. The parameterization of the model was done using the Markov chain Monte Carlo method [Tuomi et al., 2009]. No assumptions were made about the carbon fluxes between the different soil carbon pools before the parameterization.

[14] The climatic dependence of the decomposing rate $k$ of the Yasso07 carbon pools is calculated from the equation

$$
k_{i}=\alpha_{i} \exp \left(\beta_{1} T+\beta_{2} T^{2}\right)\left(1-\exp \left[\gamma P_{a}\right]\right)
$$

Here the subscript $i$ denotes the six different carbon pools, $T$ is air temperature $\left({ }^{\circ} \mathrm{C}\right), P_{a}$ is the annual precipitation $(\mathrm{m}), \alpha_{i}$ is the turnover rate (for $\mathrm{T}=0^{\circ}$ and $P_{a} \rightarrow \infty$, since $\gamma$ is negative) and $\beta_{1}=7.6 \cdot 10^{-2}{ }^{\circ} \mathrm{C}^{-1}, \beta_{2}=-8.9 \cdot 10^{-4}{ }^{\circ} \mathrm{C}^{-2}$ and $\gamma=$ $-1.27 \mathrm{~m}^{-1}$ are fitted parameters [see Tuomi et al., 2009]. These parameters imply that increased temperature enhances the decomposition rate somewhat more in Yasso07 than in CBALANCE (typically, e.g., at $17^{\circ} \mathrm{C}$, by $8.1 \%{ }^{\circ} \mathrm{C}^{-1}$ and $6.1 \%{ }^{\circ} \mathrm{C}^{-1}$, respectively). The turnover times of the pools in Yasso07 are shown in Table 1.

[15] The temperature dependence was adapted from an earlier study [Tuomi et al., 2008]. For the dependence of precipitation several different formulations were studied and the best one was selected. Air temperature and precipitation (rather than soil temperature and moisture) are used as driving variables mainly because of the data used in the development of the model. This choice was based on (1) the availability and reliability of the data used to develop the model and (2) availability of the driver variables needed to use the model. The soil temperature and moisture are functions of air temperature, precipitation, characteristics of the soil and vegetation, but a database of soil temperature and moisture reliable enough for use in the development of a global model is missing. Therefore, the reliability of the soil characteristics calculated by JSBACH or any other global scale biosphere model remains quite uncertain. The amount of soil carbon as well as soil temperature and soil moisture also change between different soil layers and this brings further complication in modeling the system properly.

[16] The Yasso model has been developed using large data set that includes many different ecosystems and a wide range of climatic conditions [Tuomi et al., 2009], covering most conditions encountered in a global climate model. It has been shown that this model provided estimates of litter decomposition and soil carbon storage without any systematical error due to different climatic conditions, ecosystem types or geographical location [Tuomi et al., 2009]. This supports the use of air temperature and precipitation in lieu of soil temperature and moisture in large-scale calculations.

[17] Overall, the parameterization consists of over 20 different parameters including mass flows between different pools, climatic dependencies, decomposition rates of different pools and mass flow from labile pools to humus. For the mass flows between different labile pools this model produced four significant pathways [see Tuomi et al., 2009]. In addition, this approach provides posterior uncertainties of the parameters and thus enables computation of the model results' uncertainties. 
Table 2. The Micrometeorological Measurement Sites

\begin{tabular}{llll}
\hline Abbreviation & \multicolumn{1}{c}{ Site } & \multicolumn{1}{c}{ Location } & Vegetation \\
\hline BR-Tap & Tapajos, Brazil & $2^{\circ} 51^{\prime} \mathrm{S}, 54^{\circ} 58^{\prime} \mathrm{W}$ & tropical rainforest \\
DK-Sor & Sorø, Denmark & $55^{\circ} 29^{\prime} \mathrm{N}, 11^{\circ} 38^{\prime} \mathrm{E}$ & temperate deciduous \\
ES-VDA & Val d'Alinya, Spain & $42^{\circ} 09^{\prime} \mathrm{N}, 1^{\circ} 26^{\prime} \mathrm{E}$ & subalpine grassland \\
FI-Hyy & Hyytiälä, Finland & $61^{\circ} 51^{\prime} \mathrm{N}, 24^{\circ} 17^{\prime} \mathrm{E}$ & evergreen coniferous \\
FR-Pue & Puéchabon, France & $43^{\circ} 44^{\prime} \mathrm{N}, 3^{\circ} 36^{\prime} \mathrm{E}$ & Mediterranean evergreen \\
HU-Bug & Bugac, Hungary & $46^{\circ} 41^{\prime} \mathrm{N}, 19^{\circ} 36^{\prime} \mathrm{E}$ & grassland \\
HU-Mat & Matra, Hungary & $47^{\circ} 51^{\prime} \mathrm{N}, 19^{\circ} 44^{\prime} \mathrm{E}$ & grassland \\
IT-Cpz & Castelporziano, Italy & $41^{\circ} 42^{\prime} \mathrm{N}, 12^{\circ} 22^{\prime} \mathrm{E}$ & $20007-2006$ \\
\hline
\end{tabular}

[18] In the model the incoming nonwoody litter is divided into the EWAN pools according to the chemical composition of each PFT [Trofymow et al., 1998; Berg et al., 1991a, 1991b; Gholz et al., 2000] whereas woody litter is allocated to the pool of woody litter. Woody litter is transferred from this pool at a lower rate and divided into the EWAN pools, again, according to the chemical composition. There is a fixed fraction (0.040) of mass flow from labile pools to the humus pool.

\subsection{Simulations}

[19] To study how the results of these two soil carbon models compare to each other at the global scale, similar global-scale simulations were run for both model formulations. We ran ECHAM5/JSBACH prescribing observed sea surface temperatures (SSTs) and sea-ice cover [AMIP Project Office, 1996]. To initialize the soil carbon pools for ECHAM5/JSBACH we first ran ECHAM5/JSBACH for 10 years without interactive soil carbon, and stored the input data needed by CBALANCE (NPP, LAI, soil temperature and humidity) and Yasso07 (NPP, LAI, air temperature and precipitation). These data were then used in spin-up runs with CBALANCE and Yasso07, in which the carbon produced by the biosphere was allocated to the different carbon pools and the soil carbon thus slowly accumulated. The soil carbon pools of CBALANCE needed a run for 1080 years and Yasso07 for 3000 years to stabilize. The spin-up time period was longer for Yasso07 because of its lower decomposition rate for the slow (humus) pool.

[20] After the soil carbon pools had reached equilibrium in the spin-up runs, these initial pool sizes were used in ECHAM5/JSBACH simulations employing the respective soil carbon models, CBALANCE and Yasso07. A stabilization run with the entire ECHAM5-JSBACH was first made with constant atmospheric $\mathrm{CO}_{2}$ concentration (350 ppm) for years 1957-1976. This was followed by a run for years 1977-2006 in which the atmospheric $\mathrm{CO}_{2}$ concentration was allowed to vary freely, according to the simulated exchange of fluxes with the land carbon components. Weather data were generated by the ECHAM5 model using measured SST. No anthropogenic emissions were included in these simulations, and there was no interactive ocean carbon cycle (i.e., carbon fluxes through the ocean surface were set to zero). Thus the resulting changes in the atmospheric $\mathrm{CO}_{2}$ were driven solely by the response of the terrestrial carbon cycle to climatic conditions. Below, the simulations using CBALANCE and Yasso07 are referred to as Cba-JEM (CBALANCE-JSBACH-ECHAM5-Model) and Y07-JEM (Yasso07-JSBACH-ECHAM5-Model).

\subsection{Evaluation Data}

[21] We used carbon stock and $\mathrm{CO}_{2}$ exchange data to evaluate the models. The carbon stock data were obtained from the Oak Ridge National Laboratory [Zinke et al., 1986] (http://cdiac.ornl.gov/ndps/ndp018.html). This data set consists of soil organic carbon contents in the topmost $1 \mathrm{~m}$ layer of over 4000 soil profiles covering all Holdridge life zones and all continents except Africa and Antarctica. We used only 3677 of these profiles, excluding the measurement points located in wetlands, because the vegetation description of JSBACH does not include ecosystem types for wetlands. The evaluation was made by comparing the average soil organic carbon content at each measurement site with the model result at the grid point closest to the measurement. The global values of soil carbon stocks were calculated as a sum of all the land grid points of the model and they give a value for the topmost one meter. In the measurements, bulk density was used in calculating the carbon stock of the soil [Zinke et al., 1986]. When the carbon content of the soil is calculated in the model, information of the bulk density is not needed, since the model calculates the carbon content of soil as a difference between litter fall and decomposition.

[22] We used ecosystem scale-flux data to compare modeled $\mathrm{CO}_{2}$ exchange with measurements. The eddy covariance method is widely used to assess the exchange of water vapor, energy and $\mathrm{CO}_{2}$ across a range of biomes [Baldocchi et al., 2001]. We compared the modeled $\mathrm{CO}_{2}$ flux to the flux measured at eight locations, selected so as to cover ecosystems that are important for the global carbon cycle. The details of the measurement sites are described in Table 2. They include five forest and three grassland sites. The forest sites include the Hyytiälä Scots pine forest in Finland (FI-Hyy) in the boreal zone, a temperate beech forest in Sorø, Denmark (DK-Sor) [Pilegaard et al., 2003], a rain forest site located in Tapajós, Brazil (BR-Tap) and two Mediterranean holm oak forests in Puéchabon, France (FR-Pue) [Allard et al., 2008] and Castelporziano, Italy (IT-Cpz) [Reichstein et al., 2002]. Out of the three grassland sites, HU-Mat and HU-Bug are located in Hungary. They are both semiarid sandy grasslands. HU-Bug is partially managed by grazing [Balogh et al., 2007; Nagy et al., 2007]. ES-VDA is a subalpine seminatural pasture on the Spanish Pyrenees [Gilmanov et al., 2007]. Then compare the model results with the measurement data we chose, for each site, the closest grid point and the PFT equivalent with the measurement site.

[23] Modeled Net Ecosystem Exchange (NEE) was compared with measured NEE, and modeled total ecosystem respiration (TER) with measured TER. Both modeled and measured TER include both autotrophic and heterotrophic 
Table 3. Average Soil Carbon Stocks and Litter Flux During the Simulation Period 1977-2006 and the Change in the Carbon Stocks Expressed as the Difference Between Mean Values for the Last 3 Years and the First 3 Years of the Simulation Period ${ }^{\mathrm{a}}$

\begin{tabular}{lll}
\hline & $1977-2006$ & $\Delta_{(2004-2006-1977-1979)}$ \\
\hline Cba-JEM & & \\
Fast & 98 & -3.8 \\
Slow & 2756 & +2.0 \\
Total soil carbon & 2853 & -1.8 \\
Living biomass & 527 & -2.1 \\
Total litter flux & 77 & -2.9 \\
Total biosphere carbon & 3380 & -3.8 \\
Y07-JEM & & \\
EWAN & 163 & -5.1 \\
Coarse litter & 113 & -0.1 \\
Humus & 1201 & -2.3 \\
Total soil carbon & 1477 & -7.6 \\
Living biomass & 526 & -2.1 \\
Total litter flux & 77 & -2.9 \\
Total biosphere carbon & 2003 & -9.7 \\
\hline
\end{tabular}

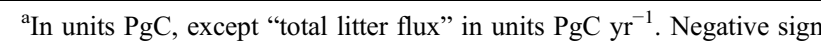
thus denotes a decrease in soil carbon stock or litter flux.

respiration. Since we only modified the heterotrophic respiration in the two model formulations (Y07-JEM and Cba-JEM), model results for heterotrophic respiration are also shown, as this allows us to see directly the differences that the different soil carbon models impose on $\mathrm{CO}_{2}$ fluxes. It must be remembered during this comparison that the eddy covariance method measures only the carbon dioxide exchange (NEE) between atmosphere and vegetation and therefore it always represents the difference between two fluxes, the downward flux $\left(\mathrm{CO}_{2}\right.$ assimilation) and the upward flux (respiration). Therefore, the total ecosystem respiration (TER) is not measured directly during daytime. Instead, it has been calculated with temperature dependency of respiration deduced from nighttime measurements [Aubinet et al., 2000]. Furthermore, TER is a sum of seasonally varying autotrophic respiration and heterotrophic respiration.

[24] The years of measurement data used are shown in Table 2. We used all the years available to obtain a general behavior monthly mean values at each site. Monthly averages over last 10 years (1997-2006) of the modeled $\mathrm{CO}_{2}$ fluxes as simulated by the two different soil carbon formulations were chosen for the comparison, to be roughly compatible with the years of measurement data. We wish to emphasize that we did not perform any tuning of our model results in the comparison to field data.

\section{Results}

\subsection{Comparison of the Two Soil Carbon Models to Measurements}

\subsubsection{Comparison of Global Estimates for Carbon Storage}

[25] The total amount of soil carbon for Cba-JEM was $2853 \mathrm{PgC}$ and for Y07-JEM $1477 \mathrm{PgC}$ (Table 3). These values are averages over the simulation period 1977-2006 during which the atmospheric $\mathrm{CO}_{2}$ concentration was allowed to vary. The observational estimates for soil carbon in the topmost meter range between 1500 and $2000 \mathrm{PgC}$ [Houghton, 2007; Bonan, 2008]. Thus the Y07-JEM result is close to the observational estimate, whereas the Cba-JEM result exceeds it substantially.

[26] The relative contributions by stable and more labile carbon pools differed between the model versions. In Cba-JEM the slow pool contained as much as $96.6 \%$ of the total soil carbon, whereas in Y07-JEM $81.3 \%$ of soil carbon was in stable form while the EWAN pools contributed $11.0 \%$ and coarse litter $7.7 \%$ to the total soil carbon (Table 3 ). The coarse litter pool of Y07-JEM was $113 \mathrm{PgC}$, which is one third of the literature estimate for the global litter pool, $300 \mathrm{PgC}$ [Houghton, 2007]. Here we included the coarse litter pool in the total soil carbon value of Y07-JEM; were it excluded, the total soil carbon for Y07-JEM would be $1360 \mathrm{PgC}$.

[27] The annual litter flux in both model versions was about $77 \mathrm{PgC}$. This is greater than, but quite close to, the global observational estimate of approximately $59 \mathrm{PgC} \mathrm{yr}^{-1}$ [Houghton, 2007]. The estimates for the amount of biomass in the world's terrestrial ecosystems range from 385 to $650 \mathrm{PgC}$ [Houghton et al., 2009]. Both models give results that fall in the middle of this range: $527 \mathrm{PgC}$ for Cba-JEM and $526 \mathrm{PgC}$ for Y07-JEM. The similarity of these results is no surprise since both models use the same submodel for living biomass. That there is at all a slight difference is a consequence of the slightly different temperatures in the two simulations, because of different $\mathrm{CO}_{2}$ concentrations in the atmosphere (see below). The living biomass for the models includes green, wood and reserve pools. All in all, Cba-JEM predicted $69 \%$ more carbon to be located in the terrestrial biosphere than Y07-JEM and this difference was caused by soil carbon storage (see Table 3).

\subsubsection{Soil Carbon Storage in Different Ecosystems}

[28] Comparing simulated soil carbon storage to the worldwide soil carbon database for different ecosystems compiled by Post et al. [1982] and Zinke et al. [1986] showed that both models overestimated the average soil carbon content across the ecosystems (Table 4), but Y07-JEM yielded a closer estimate (an overestimate of 32\%) than Cba-JEM (an overestimate of $137 \%$ ).

[29] For all the ecosystems studied, Cba-JEM gave greater estimates for soil carbon stocks than Y07-JEM (Table 4). Both models overestimated the soil carbon stock compared to the measurements except at cool deciduous forest and at main taiga. At cool deciduous forests Y07-JEM gave a slight underestimate while Cba-JEM overestimated the carbon storage compared to measurements quite substantially. At main taiga both models underestimated the soil carbon stocks compared to the measurements. With the single exception of the main taiga ecosystem, the values given by Cba-JEM deviated more from the measurements than Y07-JEM. The high measured values in main taiga might originate from sites that are turning into wetlands and thus have anoxic conditions in soil, which slows down the decomposition processes. Neither of the models takes the anoxic conditions into account and therefore they are not applicable at these sites. The anoxic conditions are a very likely reason for the high soil carbon stocks in main taiga, since the productivity at such sites is usually small and does not explain the large carbon stocks. It is also interesting that while total estimates for global soil carbon in Y07-JEM were slightly lower than the estimate based on observations (Table 3), the model estimates for different ecosystems 
Table 4. The Amounts of Carbon Stored in Soil and Their Standard Deviation According to Measurements [Zinke et al., 1986] and the Two Model Formulations for All Data and for Eight Ecosystems That Had More Than 95 Measurements $^{\mathrm{a}}$

\begin{tabular}{|c|c|c|c|c|}
\hline Description & Measurements $\left(\mathrm{kg} \mathrm{m}^{-2}\right)$ & Y07-JEM $\left(\mathrm{kg} \mathrm{m}^{-2}\right)$ & Cba-JEM $\left(\mathrm{kg} \mathrm{m}^{-2}\right)$ & $\mathrm{N}$ \\
\hline All data & $12.2 \pm 16.3$ & $16.1 \pm 17.0$ & $28.9 \pm 19.9$ & 3766 \\
\hline Cool conifer forest & $14.1 \pm 11.2$ & $17.3 \pm 12.9$ & $29.5 \pm 18.0$ & 678 \\
\hline Cool grassland & $12.4 \pm 8.7$ & $16.6 \pm 9.2$ & $33.5 \pm 14.3$ & 655 \\
\hline Tropical humid forest & $10.3 \pm 8.9$ & $16.1 \pm 9.6$ & $26.0 \pm 11.5$ & 380 \\
\hline Warm conifer forest & $13.5 \pm 7.7$ & $18.3 \pm 7.7$ & $28.2 \pm 9.5$ & 335 \\
\hline Mediterranean scrub/wood/savanna & $6.9 \pm 5.5$ & $19.2 \pm 6.2$ & $34.0 \pm 9.1$ & 255 \\
\hline Midcontinental southern taiga & $12.1 \pm 12.0$ & $16.4 \pm 12.0$ & $26.1 \pm 12.5$ & 181 \\
\hline Main taiga & $21.1 \pm 42.6$ & $11.1 \pm 42.6$ & $15.9 \pm 42.8$ & 144 \\
\hline Cool deciduous forest & $14.2 \pm 11.6$ & $12.5 \pm 11.7$ & $22.3 \pm 14.6$ & 96 \\
\hline
\end{tabular}

${ }^{\mathrm{a}} \mathrm{N}$ is the number of the data points used in each class. The comparison is done solely by the location of the grid and measurement points. Point measurements were compared to a sum over all four PFTs of the model grid point closest to the measurement.

exceeded observations (Table 4). This apparent discrepancy is related to the uncertainty in the global mean values (Table 3 ). Estimating the global values of carbon stocks from point measurements necessarily involves interpolating data and this together with missing the peatlands in the model leads into this discrepancy.

\subsubsection{Comparison to Direct $\mathrm{CO}_{2}$ Flux Measurements at Forest Sites}

[30] Global model simulations are generally not suited for comparison with site data, because they are calibrated to reproduce large scale climate and fluxes ignoring surface heterogeneity below the grid box scale of several hundred kilometers. Nevertheless, we present here a comparison with selected site data to gain further insight in performance differences arising from the two different soil models.

[31] At the forest sites studied here, the average seasonal patterns of $\mathrm{CO}_{2}$ exchange and ecosystem respiration did not differ much between the models (Figures 1 and 2). Compared to measurements, however, both models underestimated the summertime exchange rates at FI-Hyy (Figure 1a) and DKSor (Figure 1c), and at BR-Tap (Figure 1e) the modeled seasonal cycle of NEE was reversed. At Mediterranean sites there was a problem with compatibility of the PFTs and this caused some mismatch in seasonality (Figure 2).

[32] At FI-Hyy and DK-Sor the underestimation of the fluxes was more pronounced in TER than in NEE suggesting that the model also underestimated photosynthesis (Figures 1a-1d). At FI-Hyy, Y07-JEM was able to replicate the increase of TER in July, unlike Cba-JEM (Figure 1b) and the differences between the models seen in the summertime simulation results of NEE (Figure 1a) were caused by the heterotrophic respiration. At both sites FI-Hyy and DK-Sor, both models underestimated the length of the summertime period when the forest acts as a carbon sink (Figures 1a and 1c), but the winter level of NEE was quite similar to the measurements.

[33] At the BR-Tap site the annual cycle of NEE and TER was very different from that at FI-Hyy and DK-Sor (Figures 1e and 1f). The models captured the magnitudes of measured NEE and respiration fluxes but failed in capturing the seasonal cycle (Figures 1e and 1f). The failure is connected to too strong a response of photosynthesis to drought for this rain forest site and is seen in some other biosphere models as well [Saleska et al., 2003]. At BR-Tap the climate is characterized by dry and wet seasons, the dry period extending from 15 July to 15 December [Hutyra et al., 2007]. Measurements have revealed that the rain forest is a carbon source during wet season and turns out to be a carbon sink during the dry season, since drought lowered the heterotrophic respiration but the $\mathrm{CO}_{2}$ assimilation continues [Hutyra et al., 2007]. At this site, the models are unable to replicate the photosynthesis during the dry season. According to the models the forest photosynthesizes in the wet season, acting as a carbon sink, and then turns into a carbon source during the dry season.

[34] The two Mediterranean sites (FR-Pue and IT-Cpz) have both a typical Mediterranean climate with warm and dry summers, precipitation taking mostly place in autumn and winter [Reichstein et al., 2002; Allard et al., 2008]. We chose to include FR-Pue and IT-Cpz as examples of sites with a large seasonal variation in precipitation, which is a very important factor controlling the soil carbon cycle in the ecosystems. Unfortunately, the PFT used in the global simulation for the closest grid box to these sites (temperate deciduous vegetation) did not match the actual vegetation type of temperate evergreen vegetation. This discrepancy of PFTs is seen especially in the modeled NEE cycle for FRPue with model results showing a clear annual cycle with strong carbon uptake in summer (Figure 2a) while, according to the measurements, most of the carbon uptake occurs in late winter and spring. Despite the discrepancy between PFTs, both models predict the maximum carbon uptake rates quite correctly although the ecosystem carbon release is largely overestimated by the models in wintertime. At FR-Pue the summer drought caused the forest to turn into a carbon source in August, and Y07-JEM simulated this only 1 month late, whereas Cba-JEM was 2 months late. At IT-Cpz the two models simulated NEE quite similarly (Figure 2c). The forest at IT-Cpz is able to assimilate more carbon than FRPue, since the vegetation at the site has access to ground water even during summer drought [Reichstein et al., 2002] and therefore the forest remains a carbon sink even during summer.

[35] The mismatch of the PFT did not show in the comparison of simulated and measured TER (Figures $2 b$ and $2 d$ ). At FR-Pue, Cba-JEM was successful in simulating increase of TER during first months of the year (Figure 2b), but Y07JEM lagged behind 1 month. In the autumn, however, both models underestimated TER Cba-JEM giving even a larger underestimate than Y07-JEM. This large underestimation of Cba-JEM was due to a decrease in heterotrophic respiration that resulted from the model's response to reduced soil moisture and its slow recovery from that. At IT-Cpz both models simulated the increase in TER in spring successfully, 

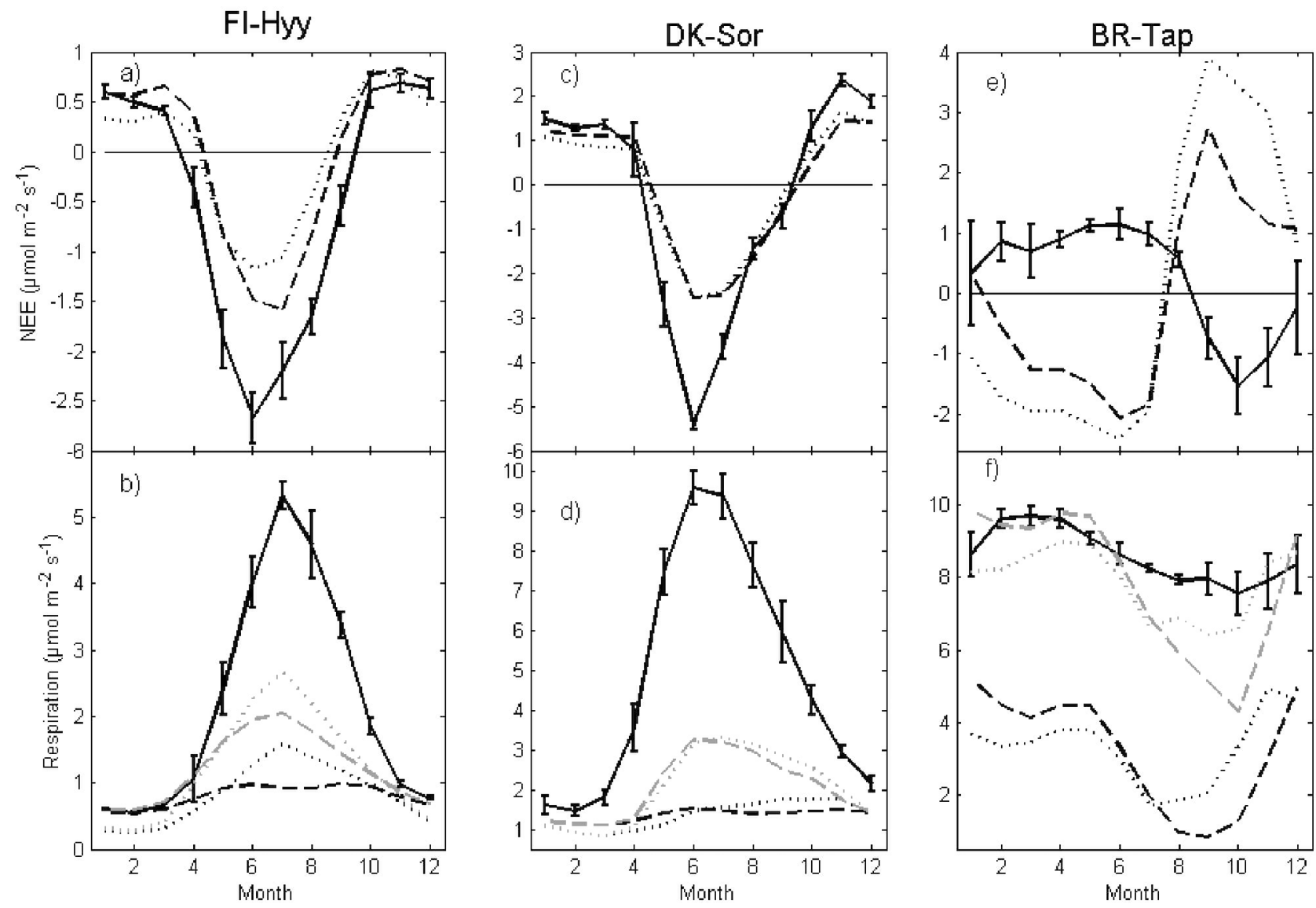

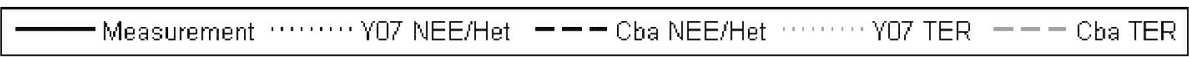

Figure 1. The measured and modeled NEE and TER and modeled heterotrophic respiration at three forest sites: (a and b) FI-Hyy, (c and d) DK-Sor, and (e and f) BR-Tap. NEE is measured, and TER is deduced from the nighttime temperature response of measured NEE. The bars added to the measurement signal show the $95 \%$ confidence intervals of the measurements computed from year-to-year variations.

but also at this site Cba-JEM showed very slow recovery from the summer drought that caused a decline in simulated TER before observed TER (Figures $2 \mathrm{~b}$ and $2 \mathrm{~d}$ ). In this respect, Y07-JEM performed better, but this is not seen as clear differences in the RMSE values (Table 5).

\subsubsection{Comparison to Direct $\mathrm{CO}_{2}$ Flux Measurements at Grassland Sites}

[36] Unlike at the forest sites, the two models show distinctly different annual cycles of NEE at the grassland sites (Figure 3). NEE simulated by Cba-JEM lags behind the measured cycle as well as behind Y07-JEM, which is more in line with measurements. At HU-Mat and HU-Bug, Y07JEM catches the month of maximum carbon uptake correctly, but Cba-JEM predicts it too late (Figures $3 \mathrm{a}$ and $3 \mathrm{c}$ ). At ES-VDA, both models predict the month of maximum carbon uptake too late (Figure 3e). In general the magnitude of the maximum carbon uptake is quite well simulated by the models at these sites, but TER is overestimated systematically (Figures 3b, 3d, and 3f) suggesting that summertime photosynthesis is overestimated by the models. At all these sites both models also clearly overestimated the wintertime carbon release. At the Hungarian sites the res- piration flux increases too early in spring in the Cba-JEM simulations, which could partially explain the lag in NEE cycle.

[37] Neither of the models was able to capture the strong response of NEE and TER to drought at the Hungarian sites (months 6-10 in Figures 3a-3d). At ES-VDA, respiration shows a strong response to drought [see also Bahn et al., 2008] and Y07-JEM is able to replicate the measured drought-related drop in the respiration flux that takes place in August, although 1 month too late (Figure 3f). At ES-VDA grazing also affects on the ecosystem fluxes, but that was no included in the model.

[38] Since the models are unsuccessful in replicating the response to drought, it was assessed whether this is caused by biases in the simulated climate as compared with that observed at the measurement sites, or whether it is rather a sign of failure in JSBACH to model the effects of drought in this ecosystem or other neglected factors. During the JuneAugust period when the effect of drought is seen in the measured fluxes at HU-Bug, the simulated air temperature was actually higher than observed (Figure 4a). The model overestimates precipitation between November and May, 

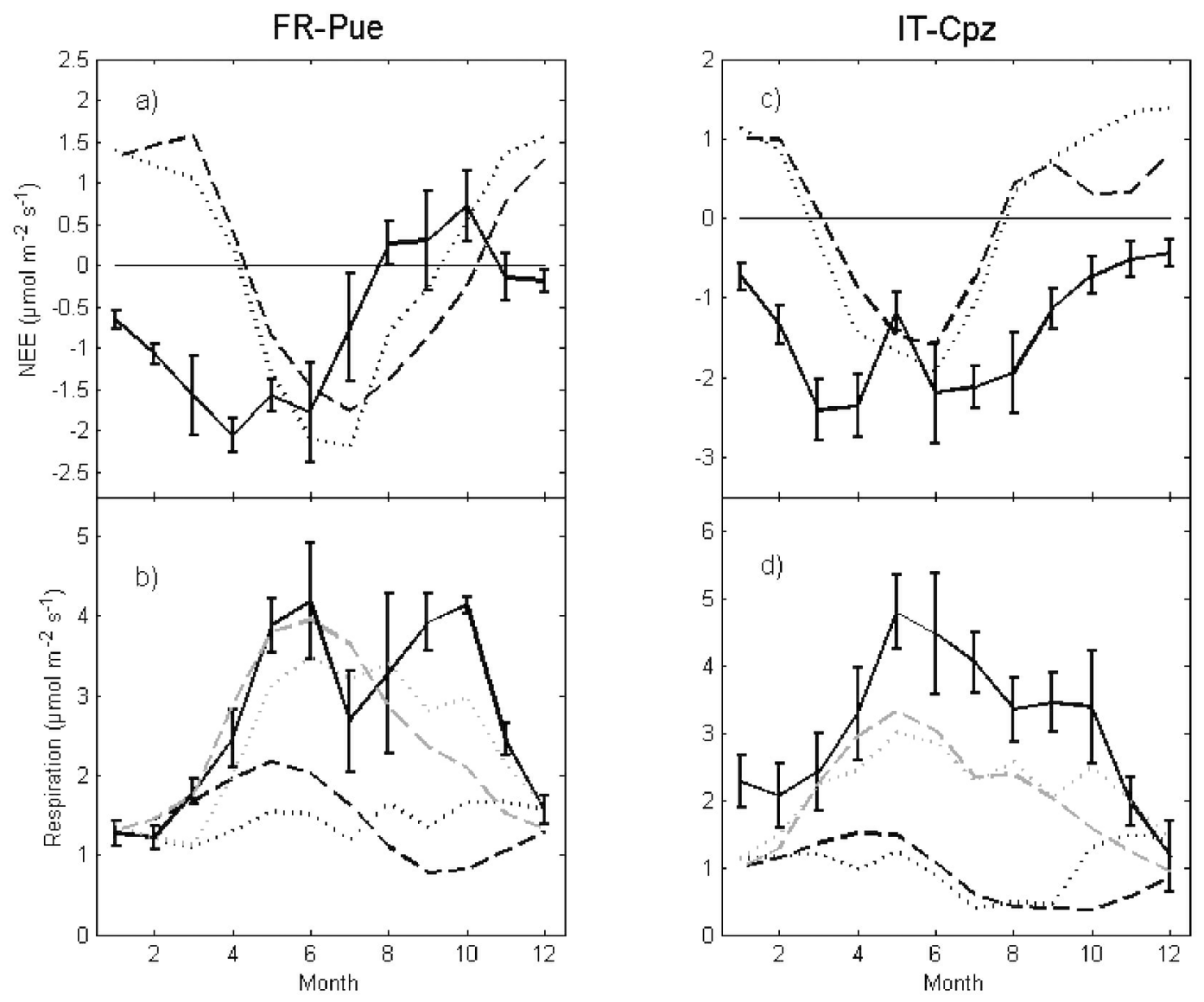

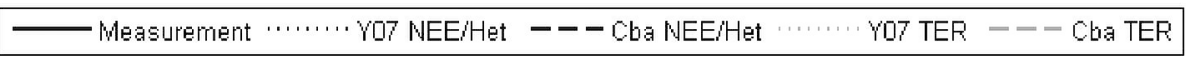

Figure 2. As in Figure 1 but for the two Mediterranean forest sites.

but does not overestimate it in summer and, in August modeled precipitation is even lower than observed (Figure 4b). Even though the greater precipitation in winter is likely to lead to more soil moisture during spring and early summer, this effect does not explain the discrepancy between measured and modeled fluxes in August. Thus, it is likely that the failure is caused by the model formulation of JSBACH rather than by the bias in the modeled climate. At the grassland sites the grass enters a dormant state during the drought and it loses its green color. Therefore, as the rain starts after the drought period, it takes a longer time for the grass to recover and start photosynthesis. This process is not modeled here and therefore, the models do not predict a clear decrease in carbon uptake during drought.

[39] In Table 5, the agreement between modeled and simulated annual cycles of NEE is quantified in terms of root mean square errors (RMSEs). Overall, the RMSEs are quite similar for the two models. Larger differences occur at HU-Bug and BR-Tap. At HU-Bug the RMSE of Y07-JEM is smaller, since Y07-JEM is able to replicate the seasonal cycle better (Figure 3c). At BR-Tap both of the models simulate opposite seasonal cycle to measurements, but the magnitude of NEE for Cba-JEM is smaller (Figure 1e) and thus its RMSE is smaller. Taking into account all the forest sites, Cba-JEM has smaller RMSE (Table 5), but if BR-Tap is left out the RMSE values of the two models are very similar (for Cba-JEM $1.28 \mu \mathrm{mol} \mathrm{m}{ }^{-2} \mathrm{~s}^{-1}$, and for Y07-JEM $\left.1.29 \mu \mathrm{mol} \mathrm{m}^{-2} \mathrm{~s}^{-1}\right)$. Note that the RMSE is calculated only for NEE, because NEE is the only directly measured variable, whereas TER is derived from NEE using modeling.

\subsection{Changes in Atmospheric $\mathrm{CO}_{2}$ and Soil Carbon Stocks in Model Simulations}

[40] The atmospheric $\mathrm{CO}_{2}$ concentration was fixed at $350 \mathrm{ppm}$ for the first 20 years (1957-1976) of the simulation

Table 5. Root Mean Square Error (in units $\mu \mathrm{mol} \mathrm{m} \mathrm{m}^{-2} \mathrm{~s}^{-1}$ ) Between Measured and Simulated Monthly Mean NEE at the Eight Measurement Sites, and Average RMSEs for the Five Forest Sites and Three Grassland Sites ${ }^{\mathrm{a}}$

\begin{tabular}{lcc}
\hline & Cba-JEM & Y07-JEM \\
\hline BR-Tap & 0.93 & 1.65 \\
DK-Sor & 1.12 & 1.11 \\
FI-Hyy & 0.63 & 0.78 \\
FR-Pue & 1.73 & 1.60 \\
IT-Cpz & 1.62 & 1.67 \\
Forest sites & 1.21 & 1.36 \\
ES-VDA & 0.73 & 0.81 \\
HU-Bug & 1.30 & 0.95 \\
HU-Mat & 0.63 & 0.57 \\
Grassland sites & 0.89 & 0.78 \\
\hline
\end{tabular}

${ }^{\mathrm{a}} \mathrm{RMSE}$, root mean square error. 

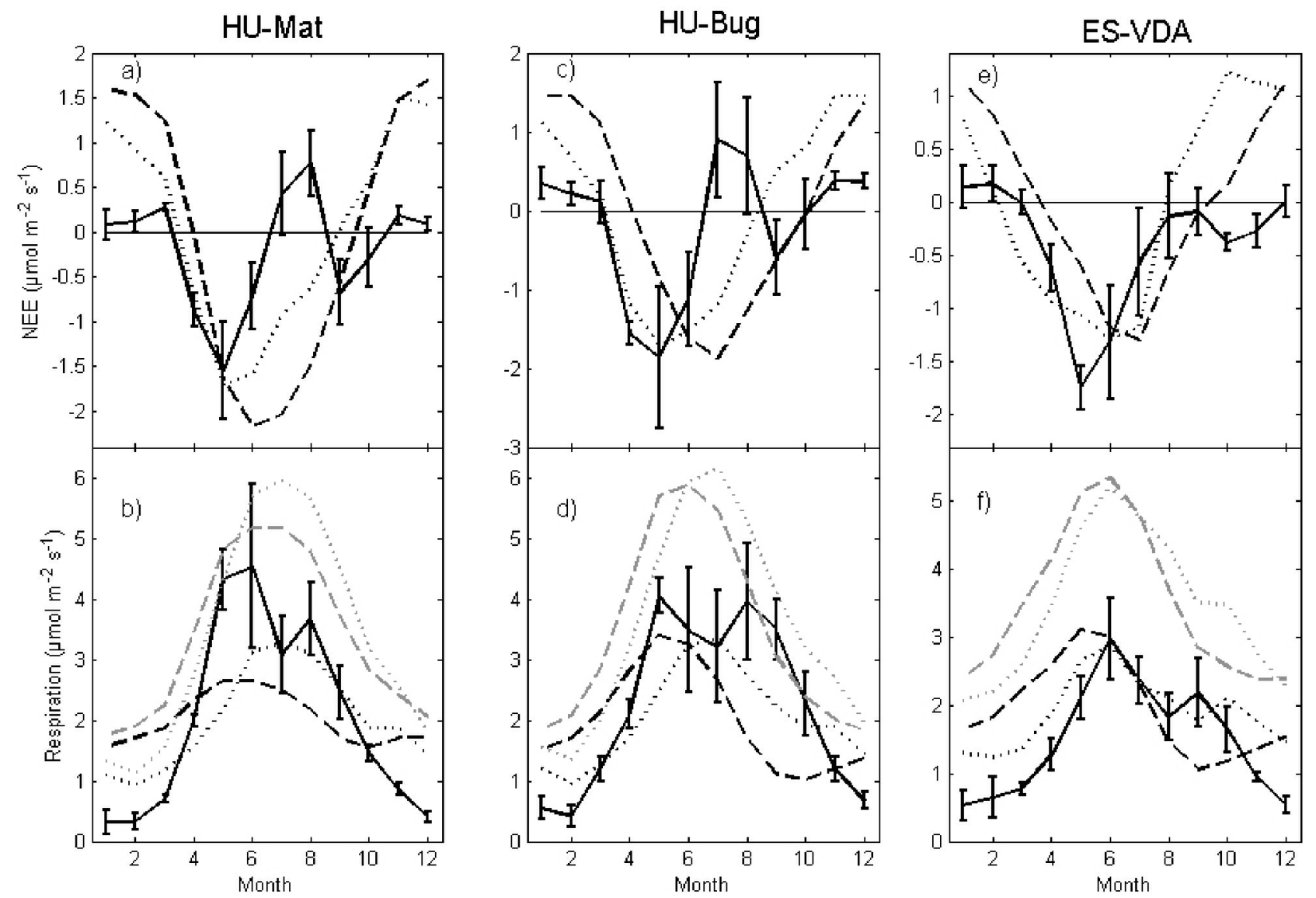

- Measurement $+\cdots \cdots \cdots$, Y 07 NEE/Het --- Cba NEE/Het $\cdots \cdots \cdots \cdots$ Y07 TER --- Cba TER

Figure 3. As in Figure 1 but for the three grassland sites.

period. For the last 30 years of the simulation, i.e., 19772006, the atmospheric $\mathrm{CO}_{2}$ concentration was allowed to vary (Figure 5). Both models show an increase in the $\mathrm{CO}_{2}$ concentration, but Y07-JEM predicts a greater increase than Cba-JEM (Figure 5). The mean difference between the last 3 years (2004-2006) and the first 3 years (1977-1979) is $4.5 \mathrm{ppmv}$ for Y07-JEM and $1.8 \mathrm{ppmv}$ for Cba-JEM. As a sensitivity test, an additional run was done with Y07-JEM for years 1977-2006, in which climate change was eliminated by using monthly mean SST and sea ice concentration averaged over the years 1957-1976. In this run, the atmospheric $\mathrm{CO}_{2}$ concentration remained nearly constant (dashed line in Figure 5). This verifies that the greater increase in atmospheric $\mathrm{CO}_{2}$ concentration simulated by Y07-JEM for years 1977-2006 is indeed caused by changing climate. Recall that anthropogenic emissions of $\mathrm{CO}_{2}$ were not included in the simulation, and the model setup excluded oceans. Therefore, the variations in atmospheric $\mathrm{CO}_{2}$ concentrations are driven exclusively by the response of the terrestrial carbon cycle to climatic conditions.

[41] By construction, in the current model setup, the extra atmospheric carbon in Y07-JEM compared to Cba-JEM originates from the land carbon cycling. Because an increase of $1 \mathrm{ppm}$ in the atmospheric $\mathrm{CO}_{2}$ equals $2.12 \mathrm{Pg}$ of carbon, it can be inferred that during the simulation period, Y07JEM released nearly $6 \mathrm{PgC}$ more carbon into the atmosphere than Cba-JEM. To study the origins of the carbon entering into the atmosphere, the amounts of carbon in different soil carbon pools and in living biomass were assessed at the beginning and end of the period 1977-2006 (Table 3). The Cba-JEM simulation shows a decrease in the fast soil carbon pool, but an increase in the slow carbon pool. Some decline also occurs in the living biomass, and thus the total biosphere carbon is decreased by $3.8 \mathrm{PgC}$. Y07-JEM shows some reduction in all the soil carbon pools as well as in the living biomass. The EWAN pools exhibited the greatest decrease, $5.1 \mathrm{PgC}$, the humus and living biomass pools both losing slightly over $2 \mathrm{PgC}$. Overall, the total biosphere carbon in the Y07-JEM model run was reduced by $9.7 \mathrm{PgC}$ during the 30 year simulation period and most of it originated from the EWAN pools.

\subsection{Continental-Scale Analysis of Carbon Budget in Years 1977-2006}

[42] Above, it was found that the increase in atmospheric $\mathrm{CO}_{2}$ concentration by Y07-JEM resulted largely from the EWAN pools. To further investigate these changes and their causes, we studied the carbon fluxes (NPP, litter flux and heterotrophic respiration), the amount of soil carbon, and the environmental variables affecting soil carbon decomposition rates: air temperature and precipitation for Y07-JEM, and soil moisture and soil temperature for Cba-JEM separately 
Weather conditions at HU-Bug
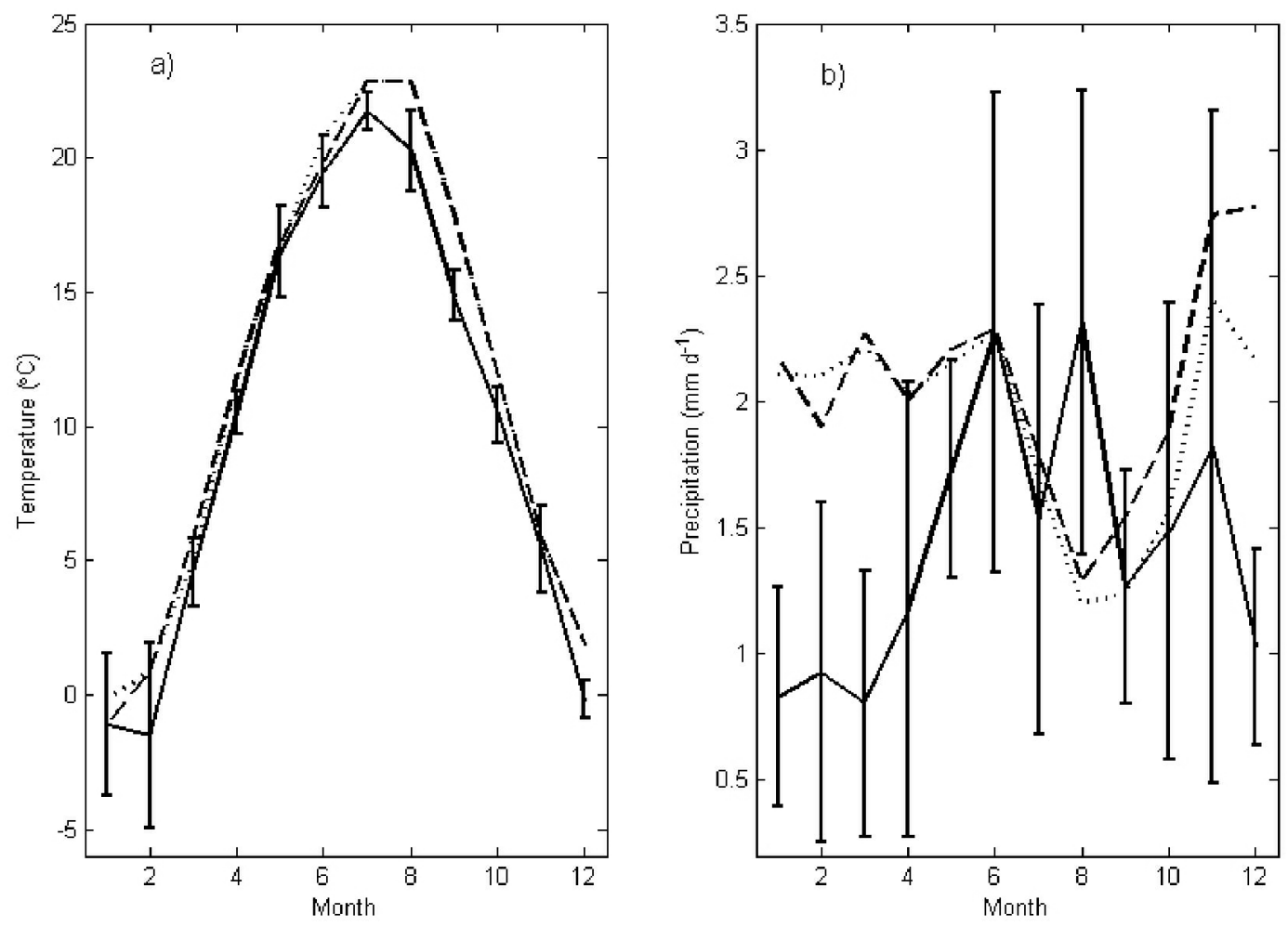

Measurement $\cdots \cdots \cdots \cdot$ Cba-JEM $---Y 07-J E M$

Figure 4. Averaged annual cycles of (a) air temperature and (b) precipitation at HU-Bug in the two model runs and as measured at the site. The error bars show the $95 \%$ confidence intervals due to natural variability.

for each continent. The impact of changes in these environmental variables on the decomposition rates was also investigated.

[43] In the Y07-JEM simulation, soil carbon decreased in all continents (Table 6). Africa and South America were the greatest contributors to the decrease in global mean of soil carbon stocks and the increase in atmospheric $\mathrm{CO}_{2}$. Soil carbon also decreased in all continents except Africa in the Cba-JEM simulation, but the decrease was generally smaller than that for the Y07-JEM simulation. This is consistent with that the increase in atmospheric $\mathrm{CO}_{2}$ is greater for Y07-JEM, than for Cba-JEM.

[44] The greater negative trend in soil carbon in the Y07JEM simulation was mainly related to the decomposition rates (DR). For Y07-JEM, the DR increased significantly in most continents as well as globally (Table 6). For Cba-JEM the trend in global-mean DR was weakly positive but statistically insignificant, the only significant trend in DR being a decrease in Africa.

[45] To understand why the DR increased more strongly in Y07-JEM than in Cba-JEM, we considered the trends in the environmental variables affecting soil carbon decomposition rates, namely: air temperature and precipitation for Y07-JEM, and soil moisture and soil temperature for Cba-JEM. In the Y07-JEM simulation, air temperature increased in all continents, whereas precipitation trends varied from one continent to another, and they were statistically insignificant except for Europe (Table 7). In the Cba-JEM simulation, soil temperature increased significantly in all continents except Australia. Soil moisture decreased in most continents with the greatest negative trend occurring in Africa.

[46] To separate the contributions of the changes in the different environmental variables to the overall trend in DR, the trends in DR were recomputed by using an averaged annual cycle of 30 years for each environmental variable at a time thus eliminating the trend occurring in that variable and revealing the role played by the other environmental variable on DR (Table 6). Thus, for example, the contribution of air (soil) temperature to the DR trends for Y07-JEM (Cba-JEM) was estimated using averaged annual cycle for precipitation (soil moisture). It can be seen that most of the increase in DR for Y07-JEM comes from the increase in air temperature. Changes in precipitation modulate the trend in $\mathrm{DR}$, but as the sign of precipitation trend varies from one continent to another, they only make a small negative contribution to the global-mean trend in DR. For Cba-JEM, increases in soil temperature gave rise to a positive trend in DR for each continent as well as globally, but this effect was counteracted by reduced soil moisture. In most continents the change in soil temperature dominated, giving rise to a slight positive trend in DR, but for Africa and Australia, 


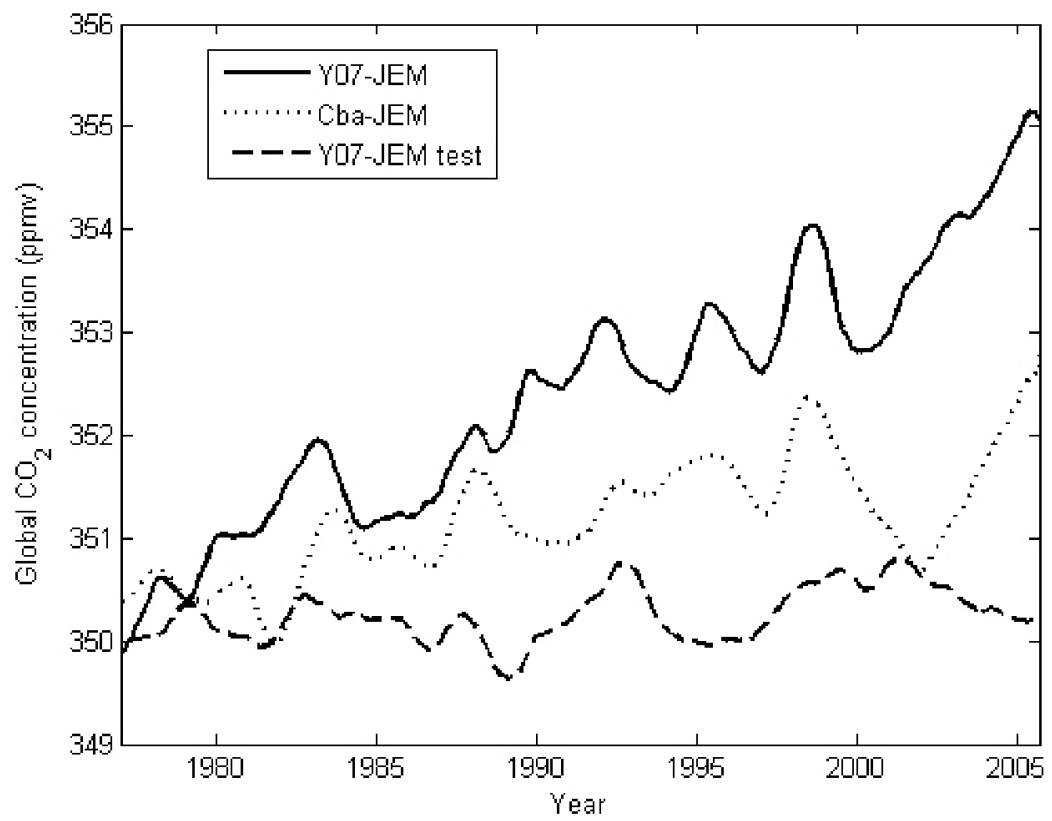

Figure 5. The global running 12 month mean atmospheric $\mathrm{CO}_{2}$ concentration from the Y07-JEM and Cba-JEM models in 1977-2006. The dashed line shows the global-mean $\mathrm{CO}_{2}$ concentration simulated by Y07-JEM, when climate change was eliminated by using repeatedly the mean annual cycle of sea surface temperature and sea ice for years 1957-1976.

reduced soil moisture resulted in a negative trend in DR, which lead to the different predictions of the soil carbon content by the two models in Africa.

[47] In conclusion, the greater negative trend in soil carbon (and greater positive trend in atmospheric $\mathrm{CO}_{2}$ ) for the Y07-JEM simulation than for Cba-JEM is related to a greater positive trend in decomposition rates. For Y07-JEM, increased air temperature is the more influential factor leading to significant increase in DR in many continents as well as globally. For Cba-JEM, reduced soil moisture halted the increase of DR that would have otherwise taken place due to increasing temperatures.

\section{Discussion}

\subsection{Model Evaluation}

[48] In this work we compared two different soil carbon model formulations in the coupled climate-carbon cycle

Table 6. Thirty Year (1977-2006) Mean Values and Trends (in Parenthesis; in Units of the Variable/30 Years) for Three Carbon Fluxes (NPP, Litter Flux, Heterotrophic Respiration), for the Amount of Soil Carbon, and for the Decomposition Rate, Separately for the Different Continents and Globally Averaged (Excluding Antarctica and Greenland) ${ }^{\mathrm{a}}$

\begin{tabular}{|c|c|c|c|c|c|c|}
\hline & $\begin{array}{c}\mathrm{NPP} \\
\left(\mathrm{kg} \mathrm{C} \mathrm{m}^{-2} \mathrm{yr}^{-1}\right)\end{array}$ & $\begin{array}{c}\text { Litter Flux } \\
\left(\mathrm{kg} \mathrm{C} \mathrm{m}^{-2} \mathrm{yr}^{-1}\right)\end{array}$ & $\begin{array}{c}\text { Respiration } \\
\left(\mathrm{kg} \mathrm{C} \mathrm{m}^{-2} \mathrm{yr}^{-1}\right)\end{array}$ & $\begin{array}{l}\text { Soil Carbon } \\
\left(\mathrm{kg} \mathrm{C} \mathrm{m}^{-2}\right)\end{array}$ & DR (r.u.) & Area $\left(10^{6} \mathrm{~km}^{2}\right)$ \\
\hline & & & Y07-JEM & & & \\
\hline South America & $1.28(-0.008)$ & $1.28(+0.005)$ & $1.28(-0.006)$ & $15.9(-0.08)^{*}$ & $4.5(+0.3)^{*}$ & 18.3 \\
\hline North America & $0.42(+0.003)$ & $0.42(+0.007)$ & $0.42(+0.007)$ & $10.6(-0.02)^{\circ}$ & $1.2(+0.04)^{*}$ & 21.4 \\
\hline Australia & $0.33(-0.07)$ & $0.33(-0.07)$ & $0.34(-0.08)$ & $10.4(-0.12)$ & $1.9(+0.08)$ & 7.8 \\
\hline Africa & $0.55(-0.01)$ & $0.55(-0.007)$ & $0.56(-0.02)$ & $9.2(-0.12)^{*}$ & $2.8(+0.2)$ & 29.9 \\
\hline Asia & $0.43(-0.007)$ & $0.44(-0.007)$ & $0.44(-0.007)$ & $10.9(-0.02)^{*}$ & $1.7(+0.04)^{*}$ & 46.2 \\
\hline Europe & $0.50(+0.03)^{*}$ & $0.50(+0.03)^{*}$ & $0.50(+0.04)^{*}$ & $13.4(-0.07)^{\circ}$ & $1.3(+0.1)^{*}$ & 6.9 \\
\hline \multirow[t]{2}{*}{ Global land } & $0.52(-0.002)$ & $0.52(-0.003)$ & $0.52(-0.006)^{\circ}$ & $10.2(-0.05)^{*}$ & $2.0(+0.1)^{*}$ & 146.9 \\
\hline & & & Cba-JEM & & & \\
\hline South America & $1.28(-0.01)$ & $1.28(-0.001)$ & $1.28(-0.003)$ & $27.6(-0.12)^{*}$ & $2.1(+0.1)$ & \\
\hline North America & $0.42(-0.04)^{\circ}$ & $0.42(-0.04)^{\circ}$ & $0.42(-0.03)$ & $22.3(-0.02)$ & $0.8(+0.04)$ & \\
\hline Australia & $0.34(+0.05)$ & $0.34(+0.05)$ & $0.35(+0.04)$ & $28.1(-0.17)^{\circ}$ & $0.6(-0.1)$ & \\
\hline Africa & $0.52(-0.06)^{*}$ & $0.56(-0.06)^{*}$ & $0.55(-0.05)^{*}$ & $19.4(+0.09)^{*}$ & $0.8(-0.1)^{*}$ & \\
\hline Asia & $0.43(-0.001)$ & $0.43(-0.002)$ & $0.43(+0.001)$ & $19.4(-0.005)$ & $1.0(+0.03)$ & \\
\hline Europe & $0.50(+0.009)$ & $0.50(+0.009)$ & $0.51(+0.01)$ & $23.2(-0.03)$ & $1.1(+0.06)$ & \\
\hline Global land & $0.52(-0.01)^{*}$ & $0.53(-0.01)^{*}$ & $0.53(-0.01)^{\circ}$ & $19.6(-0.01)^{\circ}$ & $1.1(+0.02)$ & \\
\hline
\end{tabular}

${ }^{a}$ The surface area of the continents is also given for reference. Trends significant at the $95 \%(85 \%)$ level are marked with an asterisk (circle). Autocorrelation of the time series was removed by prewhitening [Wang and Swail, 2001]. The acronym DR denotes the part of the decomposition rate that shows the influence of the environmental variables, i.e., the part in equation (1) that multiplies $\mathrm{c}_{\mathrm{i}} / \mathrm{T}_{\mathrm{i}}$ and the part in equation (2) that multiplies $\alpha_{\mathrm{i}}$. For the calculation of DR, monthly values were first calculated and after this the trend was estimated from the yearly averages. This was done to account for the nonlinear response of the DR to the climatic variables. 
Table 7. Analysis of the Contribution of the Different Environmental Variables to the Trends in DR ${ }^{\mathrm{a}}$

\begin{tabular}{|c|c|c|c|c|c|c|}
\hline & $\begin{array}{l}\text { Precipitation } \\
\left(\mathrm{mm} \mathrm{yr}^{-1}\right)\end{array}$ & $\begin{array}{c}\text { Air Temperature } \\
\left({ }^{\circ} \mathrm{C}\right)\end{array}$ & $\begin{array}{l}\text { Average DR } \\
\text { (r.u.) }\end{array}$ & $\begin{array}{l}\text { Trend in DR } \\
\text { (r.u.) }\end{array}$ & $\begin{array}{l}\text { Contribution by Air } \\
\text { Temperature (r.u.) }\end{array}$ & $\begin{array}{l}\text { Contribution by } \\
\text { Precipitation (r.u.) }\end{array}$ \\
\hline & & & Y07-JEM & & & \\
\hline South America & $1585(+9)$ & $22.2(+0.6)^{*}$ & 4.54 & $+0.28 *$ & $+0.28 *$ & -0.002 \\
\hline North America & $763(+31)$ & $4.9(+0.3)$ & 1.22 & $+0.04 *$ & +0.02 & +0.02 \\
\hline Australia & $293(-58)$ & $23.1(+0.7)^{\circ}$ & 1.88 & +0.08 & +0.17 & -0.11 \\
\hline Africa & $518(-3)$ & $23.7(+0.8)^{*}$ & 2.75 & +0.22 & $+0.14 *$ & +0.08 \\
\hline Asia & $737(-8)$ & $8.7(+0.7)^{*}$ & 1.68 & $+0.04 *$ & $+0.09 *$ & -0.04 \\
\hline Europe & $740(+48)^{\circ}$ & $7.9(+0.6)$ & 1.28 & $+0.14 *$ & +0.08 & +0.07 \\
\hline \multirow[t]{2}{*}{ Global } & $736(+8)$ & $9.3(+0.6)^{*}$ & 2.02 & $+0.09 *$ & $+0.10^{*}$ & -0.01 \\
\hline & $\begin{array}{l}\text { Soil Moisture } \\
\text { (r.u.) }\end{array}$ & $\begin{array}{c}\text { Soil Temperature } \\
\left({ }^{\circ} \mathrm{C}\right)\end{array}$ & $\begin{array}{l}\text { Average DR } \\
\text { (r.u.) }\end{array}$ & $\begin{array}{l}\text { Trend in DR } \\
\text { (r.u.) }\end{array}$ & $\begin{array}{l}\text { Contribution by Soil } \\
\text { Temperature (r.u.) }\end{array}$ & $\begin{array}{l}\text { Contribution by Soil } \\
\text { Moisture (r.u.) }\end{array}$ \\
\hline \multicolumn{7}{|c|}{ Cba-JEM } \\
\hline South America & $0.71(-0.002)$ & $22.4(+0.5)^{\circ}$ & 2.08 & +0.08 & $+0.07^{*}$ & +0.01 \\
\hline North America & $0.72(-0.01)$ & $5.5(+1.0)^{*}$ & 0.84 & +0.04 & $+0.04 *$ & -0.003 \\
\hline Australia & $0.44(+0.01)$ & $24.1(-0.05)$ & 0.59 & -0.10 & +0.03 & -0.12 \\
\hline Africa & $0.47(-0.03) *$ & $24.2(+0.9)^{*}$ & 0.78 & $-0.12 *$ & $+0.04 *$ & $-0.17 *$ \\
\hline Asia & $0.69(-0.01)^{\circ}$ & $9.2(+1.0)^{*}$ & 0.99 & +0.03 & $+0.05^{*}$ & $-0.02 *$ \\
\hline Europe & $0.78(-0.003)$ & $8.1(+0.6) *$ & 1.08 & +0.06 & $+0.01 *$ & +0.04 \\
\hline Global & $0.58(-0.009)^{*}$ & $9.55(+0.7)^{*}$ & 1.08 & +0.02 & $+0.05^{*}$ & $-0.03 *$ \\
\hline
\end{tabular}

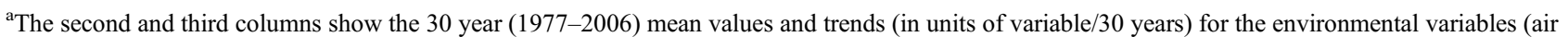
temperature and precipitation for Y07-JEM, soil temperature and soil moisture for Cba-JEM). The fourth column shows the mean value of DR, and the fifth column shows its trend (also given in Table 6). The sixth and seventh columns give the contributions of changes in the environmental variables to the trend in DR. To estimate the contribution of one environmental variable to the trend, DR was recalculated so that the trend in the other environmental variable was eliminated by using 30 year mean annual cycle for that variable. Due to the nonlinear dependence of DR on the environmental variables, the sum of the contributions by the two environmental variables differs slightly from the total trend in DR in some cases. Statistical significance of the trends is marked as in Table 6

model ECHAM5/JSBACH. The new approach, Y07-JEM, contains the Yasso07 soil model that is parameterized against a large data set with wide geographical coverage. It also has some theoretical advances compared to the older version Cba-JEM, such as a distinction of the chemical composition of incoming litter according to PFT.

[49] It is not straightforward to judge which of the model formulations succeeded better overall and yielded more realistic results. The global soil carbon estimate for Y07JEM (Table 3) was more in line with current estimates than Cba-JEM that gave quite a large overestimate. Comparison to soil carbon stock measurements [Zinke et al., 1986] also showed that Y07-JEM was closer to the observed estimates than Cba-JEM (Table 4). The better performance of Y07JEM in simulating carbon stocks might be partly caused by that soil carbon stock measurements have been used in parameterization of Y07-JEM, whereas Cba-JEM is parameterized such that in simulations for the twentieth century the observed terrestrial carbon sink and thus the observed rise in atmospheric $\mathrm{CO}_{2}$ is matched [Raddatz et al., 2007; Roeckner et al., 2010]. The rise in $\mathrm{CO}_{2}$ depends, for example, on the choice of how much carbon is transferred from fast pool to slow pool. While Table 4 indicates that Y07-JEM tends to overestimate carbon stocks, the global soil carbon content for Y07-JEM in Table 3 appears slightly too low. One possible reason for this is that JSBACH (and the estimates in Table 4) excludes peatlands that are large carbon stores globally. Were they included; the overestimate for Cba-JEM in Table 4 would become even greater.

[50] The proportions of the most stable carbon pool and other carbon pools differ greatly between the two model formulations. Y07-JEM stores more carbon in the pools with higher turnover rates. These different proportions of carbon pools with high turnover rates might influence the transient responses of the soil carbon stocks to changing climatic conditions. In the Yasso07 model, the division of soil carbon between the compartments is a result of the data used to calibrate the model [see Tuomi et al., 2009], most importantly the data on the soil carbon stocks and accumulation of soil carbon. Therefore, it can be anticipated that Y07-JEM results would be more realistic in this respect, even though there are no measurements to really verify this point.

[51] We also compared the two model formulations also at eight different direct $\mathrm{CO}_{2}$ flux measurement sites. This comparison is not straightforward, since the generic global models do not yet have the capability to model point measurements. The climatic conditions observed at a point measurement site, for example, differ from those simulated by a large-scale climatic model. Also, many aspects that have influence on the surface fluxes, such as forest age and management, and disturbances, are not modeled. Land use changes could also have altered the soil carbon stock [Pongratz et al., 2009], and these were not taken into account in our study. It is also known that soil carbon stocks are not in stationary state [Nickerson and Risk, 2009], which introduces some bias in the modeling [Wutzler and Reichstein, 2007].

[52] The coupling of photosynthesis and soil carbon fluxes on short time scales via transport of photosynthesis products into roots and rhizosphere functioning are an important part of the carbon cycle [Kuzyakov and Gavrichkova, 2010; Mahecha et al., 2010], but this has not been considered in our approach that focused only on heterotrophic respiration. To implement this, closer coupling between photosynthesis and respiration would be required.

[53] The clay content of soil impacts on the hydrological cycle of ecosystems [Markewitz et al., 2010] and the decomposing of the soil organic matter [Liski et al., 2005]. Currently, it is not included in the models used in this study, 
even though some widely used soil carbon models such as RothC [Coleman and Jenkinson, 1996] consider it to be important. The vertical profile of the clay content in forest soils [Liski and Westman, 1995] brings further complication to its addition to the model. Its inclusion, however, might improve the hydrological cycle.

[54] Despite these limitations, comparisons to $\mathrm{CO}_{2}$ flux measurements are frequently used to assess large-scale model performance. Often models are tuned to model the magnitude of point flux measurements and local observed climate is used in the comparison [Krinner et al., 2005], but this was not done in our study. A further complication to the comparison is brought by the fact that the measurements that provide only direct measures of NEE and the TER also shown in Figures 1-3 have been calculated using modeling of the nighttime measurements (see section 2.4).

[55] Considering all the limitations of this comparison, our models performed surprisingly well. Only at BR-Tap both models failed in simulating the seasonal cycle of NEE and at FR-Pue there were difficulties due to comparison between different PFTs (Figures 1-3). Successful modeling of the rain forest sites such as Tapajos has required increasing the soil depth in many biosphere models [Ichii et al., 2007; Poulter et al., 2009] and this would likely also be an important modification to JSBACH in order to improve its performance at Tapajos. Some of the model-measurement mismatch could also be related to the input of carbon into the soil via the litter flux, the realism of which was not evaluated in this study.

[56] One of our aims was to compare the two soil carbon formulations and their ability to replicate the seasonal cycle realistically. At the forest sites, there were no significant differences in model performance between Y07-JEM and Cba-JEM (Table 5), but at the grassland sites Y07-JEM was more successful than Cba-JEM in modeling the seasonal cycle (Figure 3 and Table 5). The reason for this was differences in timing of heterotrophic respiration. The largest difference between the models and measurements at these sites was the inability of JSBACH to capture the drought effect on photosynthesis which affected the results of both models. This could be partly caused by differing climatic conditions in models and measurement, but as our analysis showed (Figure 4), it was most likely due to too weak an effect of drought on the photosynthesis model or due to the fact that the dormancy state that the vegetation enters and the recovery are not modeled. Similar results have been noticed in other model studies at the Hungarian grassland sites.

\subsection{The Release of $\mathrm{CO}_{2}$ Into the Atmosphere}

[57] The climatic changes that occurred during 19772006 led to increased atmospheric $\mathrm{CO}_{2}$ concentration through release of soil carbon in both model simulations, but more so for Y07-JEM than Cba-JEM. The results imply an increase in $\mathrm{CO}_{2}$ as a response to higher temperature, which has also been inferred from other models [e.g., Friedlingstein et al., 2006] and from analysis of paleodata [e.g., Frank et al., 2010]. For Y07-JEM, atmospheric $\mathrm{CO}_{2}$ concentration increased 4.5 ppmv when global-mean land temperature increased by $0.6 \mathrm{~K}$ (Table 7), suggesting a temperature sensitivity of $7.5 \mathrm{ppmv}{ }^{\circ} \mathrm{C}^{-1}$. While this is very close to the best estimate of $7.7 \mathrm{ppmv}^{\circ} \mathrm{C}^{-1}$ given by Frank et al. [2010], this agreement has to be regarded as fortuitous, as our model setup neglects slower processes such as the ocean carbon cycle that influence the global carbon cycle. Based on [Le Quéré, 2010], oceans would uptake approximately 30\% of the carbon released be soil; however, at the same, the increase in temperature (in our case, through prescribed SSTs) would reduce the solubility of $\mathrm{CO}_{2}$ in seawater and thus act to increase the atmospheric $\mathrm{CO}_{2}$ [Le Quéré et al., 2010]. Therefore, it is difficult to assess whether the Y07JEM or Cba-JEM result is actually more realistic.

[58] An estimate of the climatic impact of the extra carbon released from soil can be obtained by considering that (1) when coupled with the MPIOM ocean model [Marsland et al., 2003], the transient climate response of ECHAM5 to a doubling of atmospheric $\mathrm{CO}_{2}$ is $2.2 \mathrm{~K}$ [Randall et al., 2007], and (2) that the radiative forcing due to increased $\mathrm{CO}_{2}$ is proportional to the logarithm of the $\mathrm{CO}_{2}$ concentration [Myhre et al., 1998]. Thus the increase of atmospheric $\mathrm{CO}_{2}$ in the Y07-JEM simulation would contribute a warming of about $\ln (355 / 350) / \ln 2 * 2.2 \mathrm{~K}=0.045 \mathrm{~K}$ in year 2006 , if the sea surface temperatures were simulated interactively. Regarding temperature change, it should also be noted that our model simulations feel the impact of anthropogenic greenhouse gas emissions only through the SSTs prescribed from observations. Although the global-mean temperature over continents is mainly determined by the SSTs [Hoerling et al., 2008], the lack of radiative forcing due to anthropogenic emissions slows down the warming over the continents slightly. Also, the modeled natural variability may not be in phase with the real world, causing the modeled continental temperature trends in Table 7 to deviate from observed trends.

[59] Our model setup only simulated the response of soil carbon storage to changing climate. In reality, the increasing atmospheric $\mathrm{CO}_{2}$ concentration also increases the NPP and thus influences the heterotrophic respiration via a greater litter input. It can be seen in Table 6 that the NPP, heterotrophic respiration and litter flux all remain in stationary state (i.e., the difference between them does not change). Also, because our model simulations do not include anthropogenic $\mathrm{CO}_{2}$ emissions, the trends in atmospheric $\mathrm{CO}_{2}$ concentration are much smaller than observed. Therefore, an increase in heterotrophic respiration following increased productivity from $\mathrm{CO}_{2}$ fertilization is not seen in our results, even though some modeling [Piao et al., 2009] and measurement studies [Bond-Lamberty and Thomson, 2010] suggest this. The changes in the soil carbon stock are also so small in the simulation period of 30 years that the changes that caused them are not seen in the flux estimates.

[60] Nevertheless, our results suggest that the increase in atmospheric $\mathrm{CO}_{2}$ concentration resulting from increased mineralization of soil organic matter with warming climate could be significantly underestimated by the commonly used $\mathrm{Q}_{10}$ approach of global climate models. This emphasizes the need for improving our understanding of soil carbon processes and incorporating the most recent knowledge into global scale models in order to improve the modeling of climate.

\section{Conclusions}

[61] In this study we compared two different soil carbon model formulations in the coupled climate-carbon cycle 
model ECHAM-JSBACH and analyzed their performance by comparing model estimates to measurements of global soil carbon stocks, ecosystem soil carbon stocks and direct $\mathrm{CO}_{2}$ flux measurements at eight measurement sites. The comparison to measured soil carbon stocks and direct $\mathrm{CO}_{2}$ flux measurements suggest better performance of Y07-JEM compared to Cba-JEM. This could be due to the different sensitivity to changes in temperature and precipitation between the models, and the ability of Yasso07 to take differences in the chemical composition of litter from different PFTs into account in the decomposition processes. Yasso07 was also parameterized using an extensive data set of real soil carbon and litter decomposition data, which improves the likelihood of that model formulation to catch climatic effects on the decomposition rate of soil organic matter.

[62] The two model formulations reacted differently to increasing temperatures of the last few decades and predicted different contributions of carbon release from terrestrial soils into the atmosphere during that time frame. This underlines the need to use different approaches to soil carbon modeling in coupled models. The next step would be to do longer simulations with a fully coupled model including oceans. Also, a study dedicated to studying model responses to climate scenarios would further highlight the impact of using Yasso07 in global climate models. All in all, by using a new way to describe the soil carbon mineralization in climate models this study tests our understanding of the carbon cycle.

[63] Acknowledgments. This study was founded by the Maj and Tor Nessling Foundation (project "Soil Carbon in Earth System Models") and supported by Maj and Tor Nessling Foundation projects 2008336 and 2009067. Center for Scientific Computing (CSC) is gratefully acknowledged for computational resources, and Tommi Bergman for technical assistance. We thank Scott R. Saleska for permission for using the Tapajos data that were downloaded from the FLUXNET site (http://www.fluxnet.ornl. gov). We thank Dario Papale for the permission to use the Castelporziano data CEAM (Fundación Centro de Estudios Ambientales del Mediterráneo) is acknowledged for the ES-VDA data. The flux data for the European sites were downloaded from the Carbo-Europe database (http://www.carboeurope.org). We thank editor Dennis Baldocchi and two anonymous reviewers whose constructive comments greatly improved this manuscript.

\section{References}

Ågren, G. I., and J. Å. M. Wetterstedt (2007), What determines the temperature response of soil organic matter decomposition?, Soil Biol. Biochem., 39, 1794-1798, doi:10.1016/j.soilbio.2007.02.007.

Allard, V., J. M. Ourcival, S. Rambal, R. Joffre, and A. Rocheteau (2008), Seasonal and annual variation of carbon exchange in an evergreen Mediterranean forest in southern France, Global Change Biol., 14, 714-725, doi:10.1111/j.1365-2486.2008.01539.x.

AMIP Project Office (1996), AMIP II guidelines, AMIP Newsl. 8, Lawrence Livermore Natl. Lab., Livermore, Calif. (Available at http://www-pcmdi. llnl.gov/projects/amip/NEWS/amipn18.php.)

Aubinet, M., et al. (2000), Estimates of the annual net carbon and water exchange of forests: The EUROFLUX methodology, Adv. Ecol. Res., 30, 113-175, doi:10.1016/S0065-2504(08)60018-5.

Bahn, M., et al. (2008), Soil respiration in European grasslands in relation to climate and assimilate supply, Ecosystems, 11, 1352-1367, doi:10.1007/s10021-008-9198-0.

Baldocchi, D., et al. (2001), FLUXNET: A new tool to study the temporal and spatial variability of ecosystem-scale carbon dioxide, water vapor and energy flux densities, Bull. Am. Meteorol. Soc., 82, 2415-2434, doi:10.1175/1520-0477(2001)082<2415:FANTTS >2.3.CO;2.

Balogh, J., Z. Nagy, S. Fóti, K. Pintér, S. Czóbel, E. R. Péli, M. Acosta, M. V. Marek, Z. Csintalan, and Z. Tuba (2007), Comparison of $\mathrm{CO}_{2}$ and $\mathrm{H}_{2} \mathrm{O}$ fluxes over grassland vegetations measured by the eddy-covariance tech- nique and by open system chamber, Photosynthetica, 45, 288-292, doi:10.1007/s11099-007-0046-9.

Berg, B., et al. (1991a), Data on needle litter decomposition and soil climate as well as site characteristics for some coniferous forest sites. Part I. Site characteristics, Rep. 41, Dep. of Ecol. and Environ. Res., Swed. Univ. of Agric. Sci., Uppsala, Sweden.

Berg, B., et al. (1991b), Data on needle litter decompo sition and soil climate as well as site characteristics for some coniferous forest sites. Part II. Decomposition data, Rep. 42, Dep. of Ecol. and Environ. Res., Swed. Univ. of Agric. Sci., Uppsala, Sweden.

Bonan, G. B. (2008), Ecological Climatology, 550 pp., Cambridge Univ. Press, New York.

Bond-Lamberty, B., and A. Thomson (2010), Temperature-associated increases in the global soil respiration record, Nature, 464, 579-582, doi:10.1038/nature08930.

Bontti, E. E., J. P. Decant, S. M. Munson, M. A. Gathany, A. Przeszlowska, M. L. Haddix, S. Owens, I. C. Burke, W. J. Parton, and M. E. Harmon (2009), Litter decomposition in grasslands of central North America (US Great Plains), Global Change Biol., 15, 1356-1363, doi:10.1111/j.13652486.2008.01815.x.

Coleman, K. and D. S. Jenkinson (1996), RothC-26.3-A model for the turnover of carbon in soil, in Evaluation of Soil Organic Matter Models-Using Existing Long-Term Datasets, NATO ASI Ser. I, vol. 38, edited by D. S. Powlson, P. Smith, and J. U. Smith, pp. 237-246, Springer, Heidelberg, Germany.

Collatz, G. J., M. Ribas-Carbo, and J. A. Berry (1992), Coupled photosynthesis-stomatal conductance model for leaves of C4 plants, Aust. J. Plant Physiol., 19, 519-538, doi:10.1071/PP9920519.

Davi, H., E. Dufrêne, C. Francois, G. Le Maire, D. Loustau, A. Bosc, S. Rambal, A. Granierm, and E. Moors (2006), Sensitivity of water and carbon fluxes to climate changes from 1960 to 2100 in European forest ecosystems, Agric. For. Meteorol., 141, 35-56, doi:10.1016/j. agrformet.2006.09.003

Farquhar, G. D., S. von Caemmerer, and J. A. Berry (1980), A biogeochemical model of photosynthesis in leaves of C3 species, Planta, 149, 78-90, doi:10.1007/BF00386231.

Frank, D., J. Esper, C. C. Raible, U. Buntgen, V. Trouet, B. Stocker, and F. Joos (2010), Ensemble reconstruction constraints on the global carbon cycle sensitivity to climate, Nature, 463, 527-530, doi:10.1038/ nature 08769 .

Friedlingstein, P., et al. (2006), Climate-carbon cycle feedback analysis, results from the C4MIP model intercomparison, J. Clim., 19, 33373353, doi:10.1175/JCLI3800.1.

Gholz, H. L., D. A. Wedin, S. M. Smitherman, M. E. Harmon, and W. J. Parton (2000), Long-term dynamics of pine and hardwood litter in contrasting environments: toward a global model of decomposition, Global Change Biol., 6, 751-765, doi:10.1046/j.1365-2486.2000.00349.x.

Gilmanov, T. G., et al. (2007), Partitioning European grassland net ecosystem $\mathrm{CO}_{2}$ exchange into gross primary productivity and ecosystem respiration using light response functions, Agric. Ecosyst. Environ., 121, 93-120, doi:10.1016/j.agee.2006.12.008.

Harrison, R. G., C. D. Jones, and J. K. Hughes (2008), Competing roles of rising $\mathrm{CO}_{2}$ and climate change in the contemporary European carbon balance, Biogeosciences, 5, 1-10, doi:10.5194/bg-5-1-2008.

Heimann, M., and M. Reichstein (2008), Terrestrial ecosystem carbon dynamics and climate feedbacks, Nature, 451, 289-292, doi:10.1038/ nature 06591 .

Hoerling, M., A. Kumar, J. Eischeid, and B. Jha (2008), What is causing the variability in global mean temperature?, Geophys. Res. Lett., 35, L23712, doi:10.1029/2008GL035984.

Houghton, R. A. (2007), Balancing the global carbon budget, Annu. Rev. Earth Planet. Sci., 35, 313-347, doi:10.1146/annurev.earth.35.031306.140057.

Houghton, R. A., F. Hall, and S. J. Goetz (2009), Importance of biomass in the global carbon cycle, J. Geophys. Res., 114, G00E03, doi:10.1029/ 2009JG000935.

Hutyra, L. R., J. W. Munger, S. R. Saleska, E. Gottlieb, B. C. Daube, A. L. Dunn, D. F. Amaral, P. B. de Camargo, and S. C. Wofsy (2007), Seasonal controls on the exchange of carbon and water in an Amazonian rain forest, J. Geophys. Res., 112, G03008, doi:10.1029/2006JG000365.

Ichii, K., H. Hashimo, M. A. White, C. Potter, L. R. Hutyra, A. R. Huete, R. B. Myneni, and R. R. Nemani (2007), Constraining rooting depths in tropical rain forests using satellite data and ecosystem modeling for accurate simulation of gross primary production seasonality, Global Change Biol., 13, 67-77, doi:10.1111/j.1365-2486.2006.01277.x

Intergovernmental Panel on Climate Change (2007), Climate Change 2007: The Physical Science Basis. Contribution of Working Group I to the Fourth Assessment Report of the Intergovernmental Panel on Climate Change, edited by S. Solomon et al., 996 pp., Cambridge Univ. Press, New York. 
Knorr, W. (2000), Annual and interannual $\mathrm{CO}_{2}$ exchange of the terrestrial biosphere: Process based simulations and uncertainties, Glob. Ecol. Biogeogr., 9, 225-252, doi:10.1046/j.1365-2699.2000.00159.x.

Knorr, W., and M. Heimann (2001), Uncertainties in global terrestrial biosphere modeling: 1. A comprehensive sensitivity analysis with a new photosynthesis and energy balance scheme, Global Biogeochem. Cycles, 15(1), 207-225, doi:10.1029/1998GB001059.

Krinner, G., N. Viovy, N. de Noblet-Ducoudré, J. Ogée, J. Polcher, P. Friedlingstein, P. Ciais, S. Sitch, and I. C. Prentice (2005), A dynamic global vegetation model for studies of the coupled atmosphere-biosphere system, Global Biogeochem. Cycles, 19, GB1015, doi:10.1029/ $2003 \mathrm{~GB} 002199$.

Kuzyakov, Y., and O. Gavrichkova (2010), Time lag between photosynthesis and carbon dioxide efflux from soil: A review of mechanisms and controls, Global Change Biol., 16, 3386-3406, doi:10.1111/j.13652486.2010.02179.x.

Le Quéré, C. (2010), Trends in the land and ocean carbon uptake, Curr. Opin. Environ. Sustainability, 2, 219-224, doi:10.1016/j.cosust.2010.06.003.

Le Quéré, C., T. Takahashi, E. T. Buitenhuis, C. Rödenbeck, and S. C. Sutherland (2010), Impact of climate change and variability on the global oceanic sink of $\mathrm{CO}_{2}$, Global Biogeochem. Cycles, 24, GB4007, doi:10.1029/2009GB003599.

Liski, J., and C. J. Westman (1995), Density of organic carbon in soil at coniferous forest sites in southern Finland, Biogeochemistry, 29, 183-197, doi:10.1007/BF02186047

Liski, J., T. Palosuo, M. Peltoniemi, and R. Sievänen (2005), Carbon and decomposition model Yasso for forest soils, Ecol. Modell., 189 , 168-182, doi:10.1016/j.ecolmodel.2005.03.005.

Mahecha, M. D., et al. (2010), Global convergence in the temperature sensitivity of respiration at ecosystem level, Science, 329, 838-840.

Markewitz, D., S. Devine, E. A. Davidson, P. Brando, and D. C. Nepstad (2010), Soil moisture depletion under simulated drought in the Amazon: Impacts on deep root uptake, New Phytol., 187, 592-607, doi:10.1111/ j.1469-8137.2010.03391.x.

Marsland, S. J., H. Haak, J. H. Jungclaus, M. Latif, and F. Röske (2003), The Max-Planck-Institute global ocean/sea ice model with orthogonal curvilinear coordinates, Ocean Modell., 5, 91-127, doi:10.1016/S14635003(02)00015-X

Myhre, G., E. J. Highwood, K. P. Shine, and F. Stordal (1998), New estimates of radiative forcing due to well mixed greenhouse gases, Geophys Res. Lett., 25, 2715-2718, doi:10.1029/98GL01908.

Nagy, Z., et al. (2007), The carbon budget of semi-arid grassland in a wet and a dry year in Hungary, Agric. Ecosyst. Environ., 121, 21-29, doi:10.1016/j.agee.2006.12.003.

Nickerson, N., and D. Risk (2009), Physical controls on the isotopic composition of soil-respired $\mathrm{CO}_{2}$, J. Geophys. Res., 114, G01013, doi:10.1029/2008JG000766.

Parton, W., J. Stewart, and C. Cole (1988), Dynamics of C, N, P, and S in grassland soil: A model, Biogeochemistry, 5, 109-131, doi:10.1007/ BF02180320.

Piao, S., P. Ciais, P. Friedlingstein, N. de Noblet-Ducoudré, P. Cadule, N. Viovy, and T. Wang (2009), Spatiotemporal patterns of terrestrial carbon cycle during the 20th century, Global Biogeochem. Cycles, 23, GB4026, doi:10.1029/2008GB003339.

Pilegaard, K., T. N. Mikkelsen, C. Beier, N. O. Jensen, P. Ambus, and H. Ro-Poulsen (2003), Field measurements of atmosphere-biosphere interactions in a Danish beech forest, Boreal Environ. Res., 8, 315-333.

Pongratz, J., C. H. Reick, T. Raddatz, and M. Claussen (2009), Effects of anthropogenic land cover change on the carbon cycle of the last millennium, Global Biogeochem. Cycles, 23, GB4001, doi:10.1029/ 2009GB003488.

Post, W. M., W. R. Emanuel, R. J. Zinke, and A. G. Stangenberger (1982), Soil carbon pools and world life zones, Nature, 298, 156-159, doi:10.1038/298156a0.

Poulter, B., U. Heyder, and W. Kramer (2009), Modeling the sensitivity of the seasonal cycle of GPP to dynamic LAI and soil depths in tropical rainforest, Ecosystems, 12, 517-533, doi:10.1007/s10021-009-9238-4.

Powers, J. S., et al. (2009), Decomposition in tropical forests: a pan-tropical study of the effects of litter type, litter placement and mesofaunal exclusion across a precipitation gradient, J. Ecol., 97, 801-811, doi:10.1111/j.13652745.2009.01515.x

Raddatz, T. J., C. H. Reick, W. Knorr, J. Kattge, E. Roeckner, R. Schnur, K.-G. Schnitzler, P. Wetzel, and J. Jungclaus (2007), Will the tropical land biosphere dominate the climate-carbon cycle feedback during the twenty-first century?, Clim. Dyn., 29, 565-574, doi:10.1007/s00382007-0247-8.

Raich, J. W., and C. S. Potter (1995), Global patters of carbon dioxide emissions from soils, Global Biogeochem. Cycles, 9, 23-36, doi:10.1029/ 94GB02723.
Raich, J. W., and W. H. Schlesinger (1992), The global carbon dioxide flux in soil respiration and its relationship to vegetation and climate, Tellus, Ser. B, 44, 81-99.

Randall, D A, et al, (2007), Climate models and their evaluation, in Climate Change 2007: The Physical Science Basis. Contribution of Working Group I to the Fourth Assesment Report of the Intergovernmental Panel on Climate Change, edited by S. Solomon et al., Cambridge Univ. Press, New York.

Reichstein, M., J. D. Tenhunen, O. Roupsard, J.-M. Ourcival, S. Rambal, F. Miglietta, A. Peressotti, M. Pecchiari, G. Tirone, and R. Valentini (2002), Severe drought effects on ecosystem $\mathrm{CO}_{2}$ and $\mathrm{H}_{2} \mathrm{O}$ fluxes at three Mediterranean evergreen sites: revision of current hypotheses?, Global Change Biol., 8, 999-1017, doi:10.1046/j.1365-2486.2002.00530.x.

Roeckner, E., et al. (2003), The atmospheric general circulation model ECHAM 5. PART I: Model description, Rep. 349, 127 pp., Max Planck Inst. for Meteorol., Harmburg, Germany.

Roeckner, E., R. Brokopf, M. Esch, M. Giorgetta, S. Hagemann, L. Kornblueh, E. Manzini, U. Schlese, and U. Schulzweida (2006), Sensitivity of simulated climate to horizontal and vertical resolution in the ECHAM5 atmosphere model, J. Clim., 19, 3771-3791, doi:10.1175/JCLI3824.1.

Roeckner, E., M. A. Giorgetta, T. Grueger, M. Esch, and J. Pongratz (2010), Historical and future anthropogenic emission pathways derived from coupled climate-carbon cycle simulations, Clim. Change, doi:10.1007/ s10584-010-9886-6.

Saleska, S. R., et al. (2003), Carbon in Amazon forests: Unexpected seasonal fluxes and disturbance-induced losses, Science, 302, 1554-1557, doi:10.1126/science. 1091165

Trofymow, J. A., et al. (1998), The Canadian Intersite Decomposition Experiment (CIDET): Project and site establishment report, Inf. Rep. $B C-X-378$, Pac. For. Cent., Victoria, B. C., Canada.

Tuomi, M., P. Vanhala, K. Karhu, H. Fritze, and J. Liski (2008), Heterotrophic soil respiration - comparison of different models describing its temperature dependence, Ecol. Modell., 211, 182-190, doi:10.1016/j. ecolmodel.2007.09.003

Tuomi, M., T. Thum, H. Järvinen, S. Fronzek, B. Berg, M. Harmon, J. A Trofymov, S. Sevanto, and J. Liski (2009), Leaf litter decompositionEstimates of global variability based on Yasso07 model, Ecol. Modell., 23, 3362-3371, doi:10.1016/j.ecolmodel.2009.05.016.

Wutzler, T., and M. Reichstein (2007), Soil apart from equilibrium consequences for soil carbon balance modelling, Biogeosciences, 4 , 125-136, doi:10.5194/bg-4-125-2007.

Yurova, A. Y., E. M. Volodin, G. I. Ågren, O. G. Chertov, and A. Komarov (2010), Effects and variations in simulated changes in soil carbon contents and dynamics on future climate projections, Global Change Biol., 16, 823-835, doi:10.1111/j.1365-2486.2009.01992.x.

Zhou, T., P. Shi, D. Hui, and Y. Luo (2009), Global pattern of temperature sensitivity of soil heterotrophic respiration $\left(\mathrm{Q}_{10}\right)$ and its implications for carbon-climate feedback, J. Geophys. Res., 114, G02016, doi:10.1029/ 2008JG000850.

Zinke, P. J., A. G. Stangenberger, W. M. Post, W. R. Emanual, and J. S. Olson (1986), Worldwide organic soil carbon and nitrogen data, NDP018, Carbon Dioxide Inf. Cent., Oak Ridge Natl. Lab., Oak Ridge, Tenn.

T. Aalto, H. Järvinen, and P. Räisänen, Climate Change Research, Finnish Meteorological Institute, PO Box 503, FI-00101 Helsinki, Finland. N. Altimir, Forest Technology Centre of Catalonia, E-25280 Solsona Spain.

J. Liski and M. Tuomi, Research Programme for Global Change, Finnish Environment Institute, PO Box 140, FI-00251 Helsinki, Finland.

Z. Nagy, Institute of Botany and Ecophysiology, Szent Istvan University, Pater 1, H-2103 Godollo, Hungary.

K. Pilegaard, Biosystems Division, Risø National Laboratory for Sustainable Energy, Technical University of Denmark, PO Box 49, DK-4000 Roskilde, Denmark.

T. Raddatz and C. Reick, Max Planck Institute for Meteorology, Bundesstrasse 35, D-20146 Hamburg, Germany.

S. Rambal, Dream CEFE-CNRS, 1919 rt. de Mende, F-34293 Montpellier, France.

S. Sevanto, Earth and Environmental Sciences Division, Los Alamos National Laboratory, PO Box 1663, Los Alamos, NM 87545, USA.

T. Thum, Le Laboratoire des Sciences du Climat et 1'Environnement, CEA-Orme des Merisiers, F-91191 Gif-sur-Yvette, France. (tea.thum@ fmi.fi)

T. Vesala, Department of Physics, University of Helsinki, PO Box 64, FI-00014 Helsinki, Finland. 